\title{
Antitumor Responses in the Absence of Toxicity in Solid Tumors by Targeting B7-H3 via Chimeric Antigen Receptor T Cells
}

\author{
Hongwei Du, ${ }^{1}$ Koichi Hirabayashi, ${ }^{1}$ Sarah Ahn, ${ }^{1,2}$ Nancy Porterfield Kren, ${ }^{1,3}$ Stephanie Ann Montgomery, ${ }^{1,4}$ Xinhui Wang, ${ }^{5}$ \\ Karthik Tiruthani, ${ }^{6}$ Bhalchandra Mirlekar, ${ }^{1,3}$ Daniel Michaud, ${ }^{1,7}$ Kevin Greene, ${ }^{4}$ Silvia Gabriela Herrera, ${ }^{1}$ Yang Xu, ${ }^{1}$ Chuang \\ Sun, ${ }^{1}$ Yuhui Chen, ${ }^{1}$ Xingcong Ma, ${ }^{1}$ Cristina Rosa Ferrone,${ }^{5}$ Yuliya Pylayeva-Gupta, ${ }^{1,3}$ Jen Jen Yeh, ${ }^{1,8,9}$ \\ Rihe Liu, ${ }^{6,10}$ Barbara Savoldo, ${ }^{1,11}$ Soldano Ferrone, ${ }^{5}$ and Gianpietro Dotti ${ }^{1,2,12, *}$ \\ ${ }^{1}$ Lineberger Comprehensive Cancer Center, University of North Carolina, Chapel Hill, NC 27599, USA \\ 2Department of Microbiology and Immunology, University of North Carolina, Chapel Hill, NC 27599, USA \\ ${ }^{3}$ Department of Genetics, University of North Carolina, Chapel Hill, NC 27599, USA \\ ${ }^{4}$ Department of Pathology \& Laboratory Medicine, University of North Carolina, Chapel Hill, NC 27599, USA \\ ${ }^{5}$ Department of Surgery, Massachusetts General Hospital, Harvard Medical School, Boston, MA 02114, USA \\ 'Division of Chemical Biology and Medicinal Chemistry, Eshelman School of Pharmacy, University of North Carolina, Chapel Hill, \\ NC 27599, USA \\ ${ }^{7}$ Department of Cell Biology and Physiology, University of North Carolina, Chapel Hill, NC 27599, USA \\ ${ }^{8}$ Department of Surgery, University of North Carolina, Chapel Hill, NC 27599, USA \\ 9Department of Pharmacology, University of North Carolina, Chapel Hill, NC 27599, USA \\ ${ }^{10}$ Carolina Center for Genome Sciences, University of North Carolina, Chapel Hill, NC 27599, USA \\ ${ }^{11}$ Department of Pediatrics, University of North Carolina, Chapel Hill, NC 27599, USA \\ 12Lead Contact \\ *Correspondence: gdotti@med.unc.edu \\ https://doi.org/10.1016/j.ccell.2019.01.002
}

\section{SUMMARY}

The high expression across multiple tumor types and restricted expression in normal tissues make B7-H3 an attractive target for immunotherapy. We generated chimeric antigen receptor (CAR) T cells targeting B7-H3 (B7-H3.CAR-Ts) and found that B7-H3.CAR-Ts controlled the growth of pancreatic ductal adenocarcinoma, ovarian cancer and neuroblastoma in vitro and in orthotopic and metastatic xenograft mouse models, which included patient-derived xenograft. We also found that 4-1BB co-stimulation promotes lower PD-1 expression in B7-H3.CAR-Ts, and superior antitumor activity when targeting tumor cells that constitutively expressed PD-L1. We took advantage of the cross-reactivity of the B7-H3.CAR with murine B7-H3, and found that B7-H3.CAR-Ts significantly controlled tumor growth in a syngeneic tumor model without evident toxicity. These findings support the clinical development of B7-H3.CAR-Ts.

\section{INTRODUCTION}

Remarkable clinical responses have been reported in B cell malignancies treated by the adoptive transfer of $\mathrm{T}$ cells redirected with a chimeric antigen receptor (CAR) specific for CD19 (Brentjens et al., 2013; Maude et al., 2014). However, developing CARTs for the treatment of solid tumors is challenging because antigens expressed on the cell surface of tumor cells are generally shared with some normal tissues, often intratumorly heterogeneous, and not broadly expressed across different tumor types (Newick et al., 2017).

$\mathrm{B} 7-\mathrm{H} 3$ is a type I transmembrane protein that belongs to the B7 immune co-stimulatory and co-inhibitory family and has two isoforms in humans, $2 \mathrm{lg}-\mathrm{B} 7-\mathrm{H} 3$ and $4 \mathrm{lg}-\mathrm{B} 7 \mathrm{H} 3$, and one

\section{Significance}

We developed CAR-Ts for targeting B7-H3 in solid tumors, which effectively controlled tumor cell growth in vitro and in orthotopic, metastatic, and patient-derived xenograft mouse models without causing detectable toxicity. Considering the broad expression of B7-H3 in solid tumors, B7-H3.CAR-Ts may provide therapeutic opportunities for cancer patients who are challenging to treat. Furthermore, we found that 4-1BB co-stimulation promotes lower PD-1 expression in B7-H3.CAR-Ts, leading to their superior antitumor activity when targeting pancreatic tumor cells that constitutively expressed PD-L1. This evidence provides further guidelines for the selection of appropriate co-stimulation for CAR-Ts in the clinical setting of solid tumors. 
A

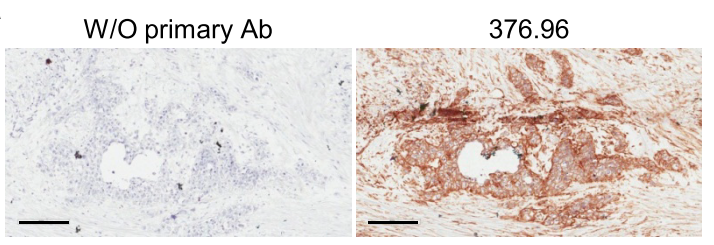

B

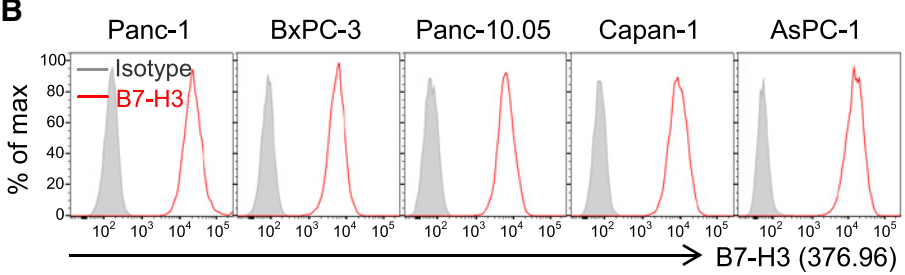

C $\begin{array}{llll}\text { Panc-1 } & \text { BxPC-3 } & \text { Panc-10.05 Capan-1 }\end{array}$ AsPC-1

D

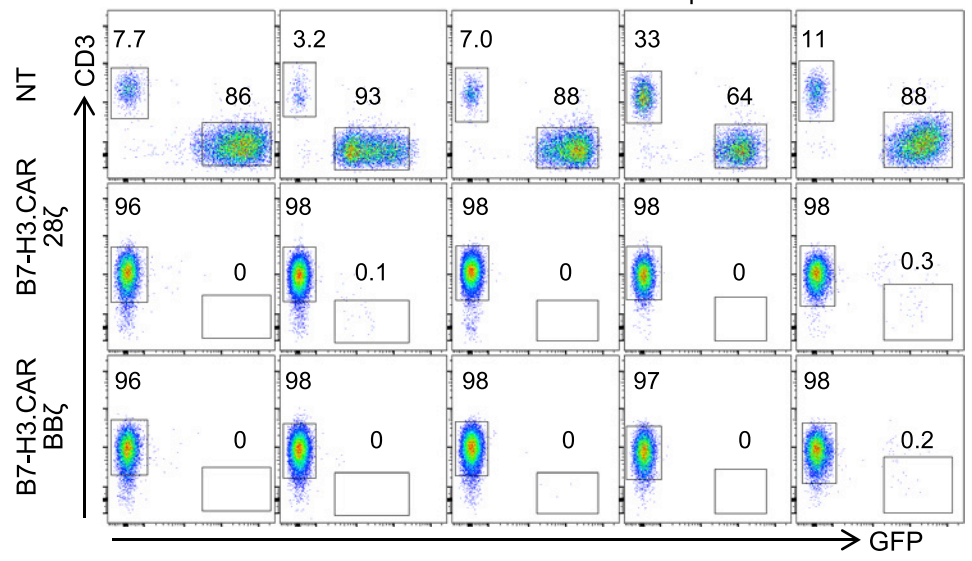

NT $\square$ B7-H3.CAR-283 $\rightleftharpoons$ B7-H3.CAR-BB\}

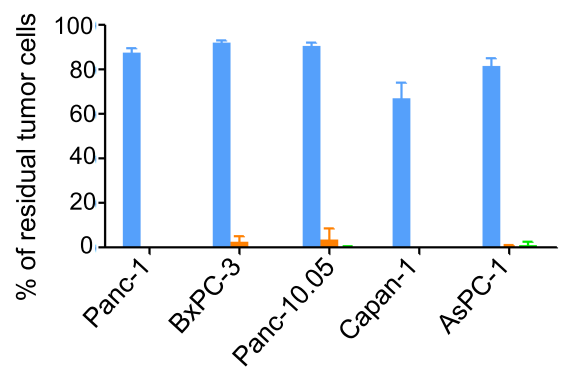

E

$\mathbf{F}$

G

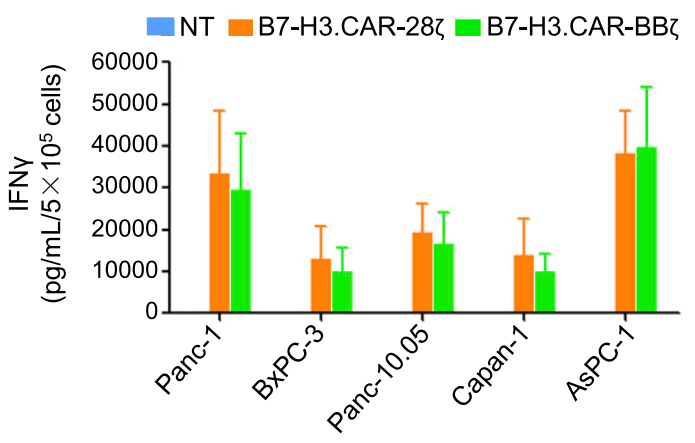

$F$ NT $\square$ B $7-H 3 . C A R-28 \zeta=B 7-H 3 . C A R-B B \zeta$

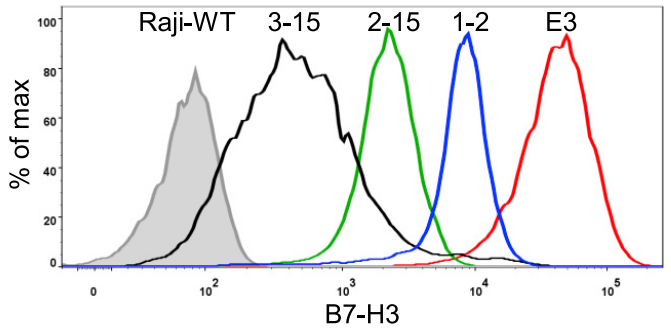

I
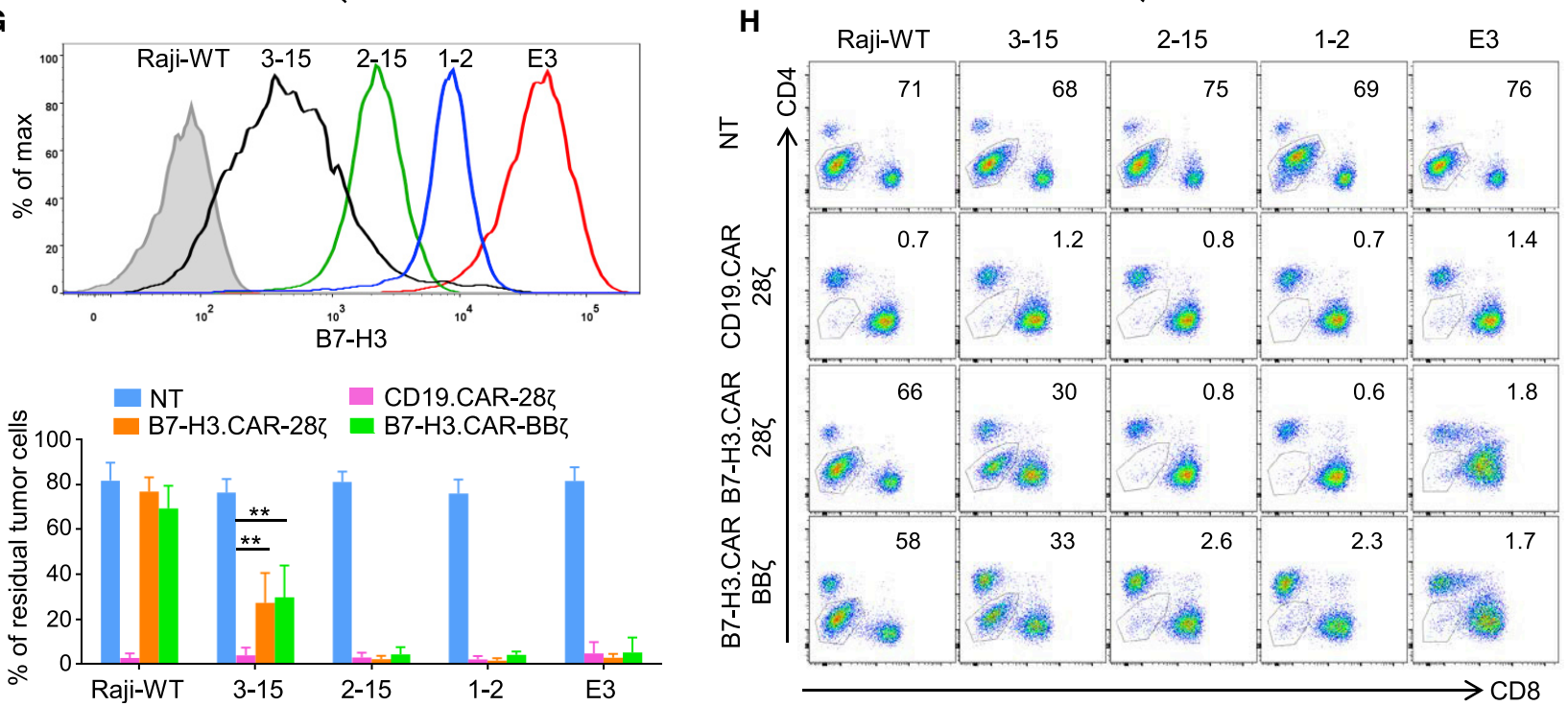

Figure 1. B7-H3.CAR-Ts Target B7-H3 ${ }^{+}$PDAC Cells

(A) Representative micrographs of B7-H3 expression in PDAC assessed by staining with the $376.96 \mathrm{mAb}$ at the final concentration of $1 \mu \mathrm{g} / \mathrm{mL}$. Slides stained only with the secondary $\mathrm{Ab}$ were used as a negative control. Scale bars, $200 \mu \mathrm{m}$. 
isoform in mice, 2lg-B7-H3, that shares $88 \%$ amino acid identity with the human 2lg-B7-H3 isoform (Chapoval et al., 2001; Steinberger et al., 2004). B7-H3 has immune inhibitory functions. It reduces type I interferon (IFN) released by T cells and cytotoxic activity of natural killer cells (Lee et al., 2017). Other studies support a negative immune regulatory role of $\mathrm{B} 7-\mathrm{H} 3$ in models of graft-versus-host disease, cardiac allograft rejection, airway inflammation, and autoimmune encephalomyelitis (Leitner et al., 2009; Prasad et al., 2004; Suh et al., 2003; Ueno et al., 2012; Veenstra et al., 2015; Vigdorovich et al., 2013). Conversely, B7-H3 has also been described as a T cell co-stimulatory molecule in vitro and in autoimmune disease models (Chapoval et al., 2001; Chen et al., 2012).

The B7-H3 protein has limited expression in normal human tissues, such as prostate, breast, placenta, liver, colon, and lymphoid organs (Hofmeyer et al., 2008; Seaman et al., 2017). However, it is aberrantly expressed in a high proportion of human malignancies (Inamura et al., 2017; Loos et al., 2010; Picarda et al., 2016; Seaman et al., 2017; Yamato et al., 2009). In addition, $\mathrm{B} 7-\mathrm{H} 3$ is found to be overexpressed by the tumor-associated vasculature and stroma fibroblasts (Inamura et al., 2017; Seaman et al., 2017). Overexpression of B7-H3 in tumor cells frequently correlates with fewer tumor-infiltrating lymphocytes, faster cancer progression, and poor clinical outcome in several malignancies, such as pancreatic ductal adenocarcinoma (PDAC), prostate cancer, ovarian cancer (OC), lung cancer, and clear cell renal carcinoma (Benzon et al., 2017; Inamura et al., 2017; Loos et al., 2009, 2010; Parker et al., 2011; Picarda et al., 2016; Qin et al., 2013; Roth et al., 2007; Yamato et al., 2009; Zang et al., 2007, 2010). Due to its broad expression across multiple tumor types, B7-H3 is an attractive target for cancer immunotherapy. B7-H3-specific monoclonal antibodies (mAbs) and antibody-drug conjugates showed antitumor activity against $\mathrm{B} 7-\mathrm{H}^{+}$tumor cells in xenograft mouse models, and phase I clinical trials showed a good safety profile (NCT01099644, NCT02381314 and NCT02982941) (Fauci et al., 2014; Kasten et al., 2017; Kramer et al., 2010; Loo et al., 2012; Seaman et al., 2017; Souweidane et al., 2018).

Here we aimed to systematically examine the safety and antitumor activity of T cells expressing a B7-H3-specific CAR.

\section{RESULTS}

\section{PDAC Expresses B7-H3 and Is Targeted by B7-H3.CAR-Ts}

Frozen human PDAC specimens were cryosectioned and stained with the B7-H3 mAb 376.96. As shown in Figure 1A,
PDAC stained strongly positive for B7-H3, with the antigen expressed by both tumor cells and surrounding stroma (Figures S1A-S1C). We generated a B7-H3.CAR using the single-chain variable fragment (scFv) derived from the B7-H3 $376.96 \mathrm{mAb}$ (Fauci et al., 2014; Imai et al., 1982; Kasten et al., 2017) and included either CD28 or 4-1BB endodomains (B7-H3.CAR-28 and B7-H3.CAR-BB', respectively) (Figure S1D). The transduction efficiency of activated $\mathrm{T}$ cells was generally greater than $60 \%$, and phenotypic analysis showed that B7-H3.CAR-Ts contained central-memory, effector-memory, and T stem cell memory, without significant differences between CD28 and 4-1BB co-stimulation (Figures S1E-S1I). B7-H3.CAR-Ts specifically recognized tumor cells expressing either the $2 \mathrm{lg}-\mathrm{B} 7-\mathrm{H} 3$ or $4 \mathrm{lg}-$ $\mathrm{B} 7-\mathrm{H} 3$ isoform of human B7-H3 (Figures S1J-S1N). The antitumor activity of B7-H3.CAR-Ts was evaluated against five human PDAC cell lines (Panc-1, BxPC-3, Panc-10.05, Capan-1, and AsPC-1) that express B7-H3 (Figure 1B). PDAC cell lines were co-cultured with control non-transduced T cell (NT), B7H3.CAR-28 $\zeta-T s$, and B7-H3.CAR-BB $\zeta-T s$ at different $T$ cell to tumor cell ratios. As shown in Figures $1 \mathrm{C}$ and 1D, B7-H3.CAR-Ts effectively controlled PDAC cell growth even at the T cell to tumor cell ratio of 1 to 5 . Cytolytic activity of B7-H3.CAR-Ts was corroborated by cytokine release (IFN- $\gamma$ and interleukin-2 [IL-2]) in the culture supernatant (Figures $1 \mathrm{E}$ and $1 \mathrm{~F}$ ), and by $\mathrm{T}$ cell proliferation in response to $\mathrm{B} 7-\mathrm{H}^{+}$target cells, as assessed by carboxyfluorescein diacetate succinimidyl ester (CFSE) dilution assay (Figure S1O). We also assessed how the density of $\mathrm{B} 7-\mathrm{H} 3$ expression in target cells affects the antitumor activity of B7-H3.CAR-Ts by generating single-cell clones of tumor cells expressing different levels of the human 4lg-B7-H3 isoform (Figure 1G). Tumor cells expressing low levels of $4 \mathrm{lg}-$ $\mathrm{B} 7-\mathrm{H} 3$, triggered significantly less activity of B7-H3.CAR-Ts even when $T$ cells were cultured with tumor cells at the high $\mathrm{T}$ cell to tumor cell ratio of 1 to 1 (Figures $1 \mathrm{H}$ and $1 \mathrm{l}$ ).

\section{B7-H3.CAR-Ts Show Antitumor Activity in PDAC Xenograft Models}

To evaluate the antitumor effects of B7-H3.CAR-Ts in vivo, we implanted the FFluc-transduced Panc-1 tumor cell line into the pancreas of NOD/SCID/gamma(c) (null) (NSG) mice. Twelve days later, mice were infused with CD19.CAR-Ts, B7-H3.CAR28ל-Ts, and B7-H3.CAR-BBל-Ts intravenously (i.v.) via tail vein injection, when the median bioluminescence intensity (BLI) of the tumors was $1.5 \pm 1.5 \times 10^{9}$ (Figure 2A). Both B7-H3.CAR28\%-Ts and B7-H3.CAR-BB $\zeta-T$ s effectively controlled Panc-1 tumor cell growth, and mice remained tumor free for up to 80 days post treatment, while the tumor grew in mice treated

(B) Expression of B7-H3 in five human PDAC cell lines stained with the $376.96 \mathrm{mAb}$ as assessed by flow cytometry.

(C and D) PDAC cell lines labeled with GFP were co-cultured with NT, B7-H3.CAR-28 -Ts, or B7-H3.CAR-BBל-Ts at the T cell to tumor cell ratio of 1 to 5 . On day 5 , PDAC $\left(\mathrm{GFP}^{+}\right)$and B7-H3.CAR-Ts $\left(\mathrm{CD}^{+}\right)$were enumerated by flow cytometry. Representative flow-cytometry plots $(\mathrm{C})$ and quantification of residual tumor cells (D) are illustrated $(n=4)$. Error bars denote SD.

(E and F) Summary of IFN- $\gamma(E)$ and IL-2 (F) released by NT, B7-H3.CAR-28ל-Ts, and B7-H3.CAR-BBל-Ts in the culture supernatant after $24 \mathrm{~h}$ of co-culture with the indicated cell lines as measured by ELISA $(n=4)$. Error bars denote SD.

(G) The Raji cell line was engineered to express h4lg-B7-H3 via retroviral gene transfer. Cells were sorted based on different expression level of 4lg-B7-H3, and single clones were expanded. B7-H3 expression of the clones was assessed by staining with the $376.96 \mathrm{mAb}$ and analyzed by flow cytometry.

( $\mathrm{H}$ and I) Representative flow-cytometry plots of Raji cells $\left(\mathrm{CD} 4^{-} \mathrm{CD} 8^{-}\right)$and T cells $\left(\mathrm{CD} 4^{+}\right.$or $\left.\mathrm{CD} 8^{+}\right)(\mathrm{H})$ and summary of residual tumor cells $(\mathrm{I}) 5$ days after Raji wildtype (WT) and Raji 4lg-B7-H3 clones were co-cultured with NT, CD19.CAR-Ts, B7-H3.CAR-28ל-Ts, or B7-H3.CAR-BBל-Ts at 1 to 1 ratio ( $n=5$ ). Error bars denote $\mathrm{SD} ;{ }^{* \star} \mathrm{p}<0.01$, one-way ANOVA with Holm-Sidak test adjusted $\mathrm{p}$ value.

See also Figure S1. 
A

Orthotopic

Panc-1, $2 \times 10^{5} \quad$ T cells i.v., $1 \times 10^{7} \quad$ Weekly imaging

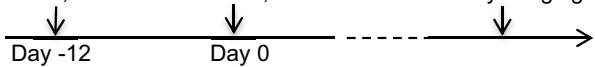

B

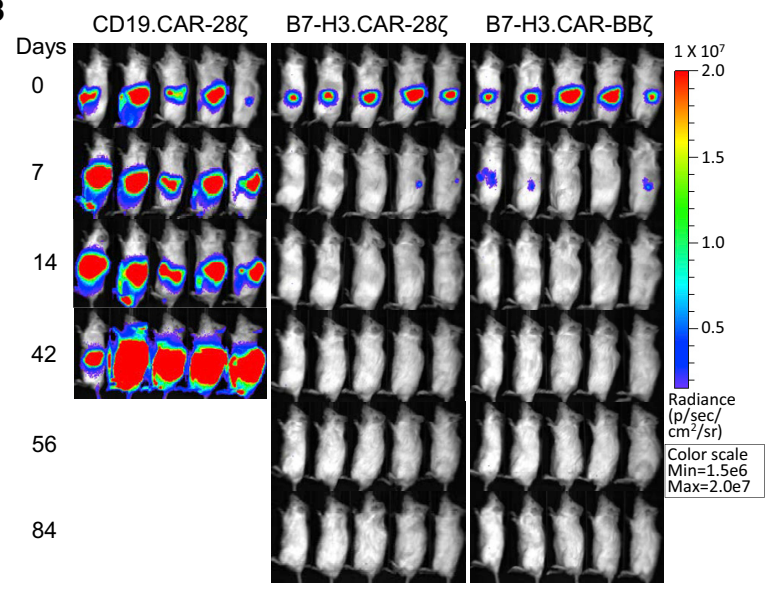

E

Panc-1, $2 \times 10^{5} \quad$ T cells i.v., $1 \times 10^{7} \quad$ Weekly imaging

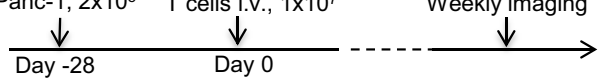

$\mathbf{F}$

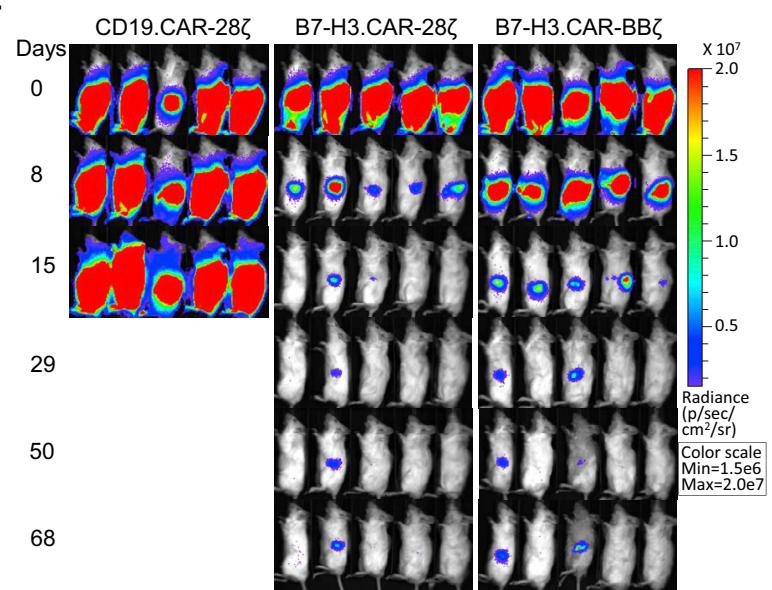

H i.v. injection

Panc-1, $1 \times 10^{6} \quad$ T cells i.v., $1 \times 10^{7} \quad$ Weekly imaging

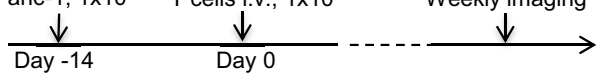

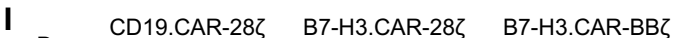

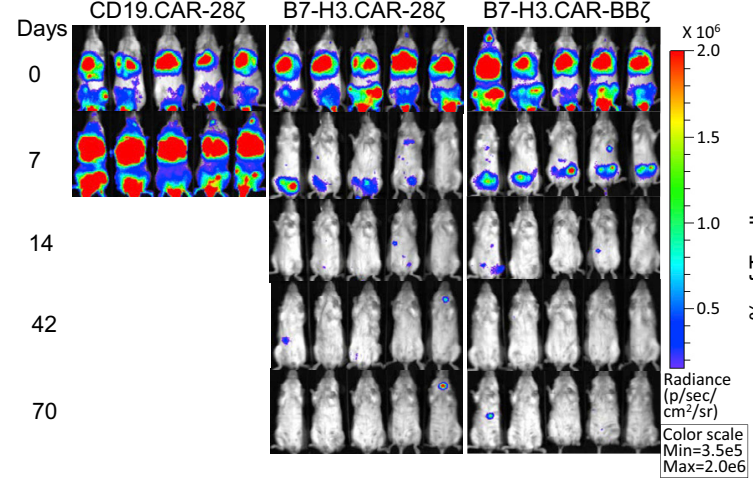

C

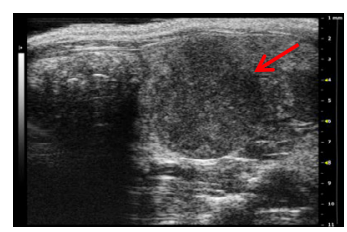

D

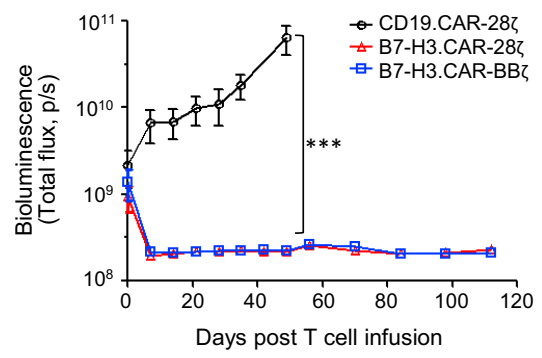

G

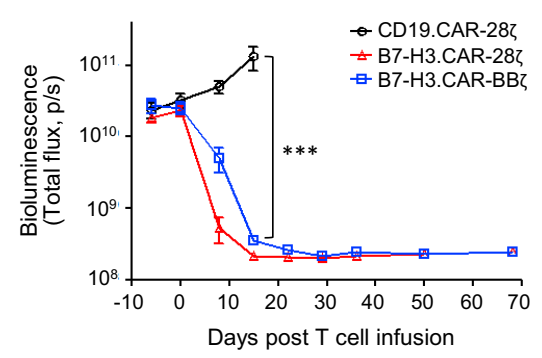

J
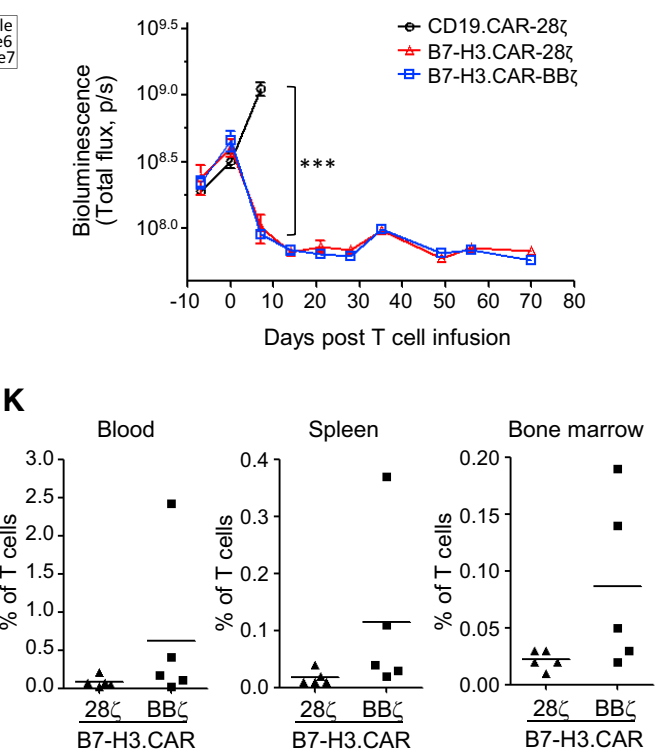

Figure 2. B7-H3.CAR-Ts Control PDAC Growth in Xenograft Models

(A) Schema of the PDAC orthotopic xenograft model infused with CAR-Ts on day 12 after tumor inoculation.

(B) Representative bioluminescence images of FFluc-Panc-1 tumor growth in the PDAC orthotopic model shown in (A). 
with control T cells (Figures 2B-2D). We also assessed the antitumor activity of B7-H3.CAR-Ts in a PDAC model with high tumor burden by delaying the infusion of T cells until day 28 post tumor injection, when the median BLI of the tumors was $2.7 \pm 1.3 \times 10^{10}$ (Figure 2E). Both B7-H3.CAR-28ל-Ts and B7-H3.CAR-BBל-Ts effectively controlled the tumor growth (Figures $2 \mathrm{~F}$ and $2 \mathrm{G}$ ). To further investigate the efficacy of B7-H3.CAR-Ts, we implemented a metastatic PDAC model by infusing Panc-1 tumor cells i.v. into NSG mice (Figure 2H). As shown in Figures $2 \mathrm{I}$ and 2J, B7H3.CAR-28\%-Ts and B7-H3.CAR-BB'-Ts, but not CD19.CAR-Ts, controlled Panc-1 tumor growth up to day 70 post treatment when the experiment was terminated. Overall, B7-H3.CAR-28 $\zeta$-Ts and B7-H3.CAR-BB $\zeta-T s$ showed comparable antitumor properties in Panc-1 orthotopic and metastatic PDAC models, and CAR-Ts persisted for up to 70 days post infusion (Figure $2 \mathrm{~K}$ ).

\section{B7-H3.CAR-Ts Show Antitumor Activity in PDAC Patient-Derived Xenografts}

PDAC patient-derived xenograft (PDAC-PDX) tumor models allow faithful recapitulation of histology, genetics, and transcriptome to the donor patient-derived tumor (Siolas and Hannon, 2013). We analyzed B7-H3 expression in early passages of three primary PDAC cell lines established from ascites of three patients (PDAC-2, PDAC-3, and PDAC-6) (Figure 3A), and cocultured them with NT, B7-H3.CAR-28 $\zeta-T s$, or B7-H3.CAR$\mathrm{BB} \zeta-\mathrm{Ts}$ at $\mathrm{T}$ cell to tumor cell ratios of 1 to 5 and 1 to 10 . As shown in Figures 3B-3D, both B7-H3.CAR-28\%-Ts and B7H3.CAR-BB $\zeta-T s$ effectively eliminated PDAC cells from the coculture. Cytolytic activity was corroborated by cytokine release (IFN- $\gamma$ and IL-2) in the culture supernatant (Figures 3E and 3F), and by antigen-specific $T$ cell proliferation as assessed by CFSE dilution assay (Figure 3G). PDAC-PDX tumor fragments were orthotopically implanted into the pancreas of NSG mice. We confirmed that PDAC-PDX retained the expression of $\mathrm{B} 7-\mathrm{H} 3$ in vivo upon engraftment in NSG mice (Figure $3 \mathrm{H}$ ). Three weeks post PDAC-PDX tumor implantation, mice received CD19.CAR-Ts, B7-H3.CAR-28ל-Ts, or B7-H3.CAR-BBל-Ts i.v.. In the first PDAC-PDX model both B7-H3.CAR-28 $\zeta-T$ s and B7-H3.CAR-BB $\zeta-T s$ controlled tumor growth and eliminated the tumor in 2 of 5 mice in both groups by day 31 upon T cell infusion when the experiment was terminated because mice treated with CD19.CAR-Ts developed signs of graft-versus-mouse disease characterized by weight and fur loss and lethargy (Figures $3 \mathrm{I}$ and $3 \mathrm{~J}$ ). In the second PDAC-PDX model, a sustained antitumor effect ( $>80$ days) was observed without occurrence of graft-versus-mouse disease (Figure $3 \mathrm{~K}$ ).
B7-H3.CAR-Ts Expressing 4-1BB Have Low Expression of PD-1 and Superior Antitumor Activity when Targeting PDAC Constitutively Expressing PD-L1

In the xenograft models using the Panc-1 PDAC cell line, B7-H3.CAR-28\%-Ts and B7-H3.CAR-BB $\zeta-T s$ showed comparable antitumor activity. To assess whether CD28 versus $4-1 \mathrm{BB}$ co-stimulation may have a different outcome in tumor rechallenge experiments, mice that cleared Panc-1 PDAC tumor cells upon infusion of B7-H3.CAR-28\%-Ts and B7-H3.CAR-BBל-Ts were rechallenged with tumor cells (Figure 4A). Both B7-H3.CAR-28ל-Ts and B7-H3.CAR-BB'-Ts had comparable and sustained antitumor activity (Figures $4 B$ and $4 C$ ) without showing significant differences in memory $T$ cell subsets (Figures S2A-S2D). By contrast, circulating B7-H3.CAR-BB $3-T$ s were numerically more abundant than B7-H3.CAR-28ל-Ts (Figures 4D-4F) and showed lower expression of PD-1 in $\mathrm{CD}^{+} \mathrm{T}$ cells, but not in $\mathrm{CD}^{+} \mathrm{T}$ cells (Figures $4 \mathrm{G}-4 \mathrm{I}$ and $\mathrm{S} 2 \mathrm{E}$ ). At later time points, B7-H3.CAR-BB $\zeta-T s$ also showed lower TIM3 expression (Figures S2F and S2G). The lower expression of PD-1 in B7-H3.CAR-BB $\zeta-T s$ was confirmed in vitro when B7-H3.CAR$28 \mathrm{\zeta}-\mathrm{T}$ s and $\mathrm{B} 7-\mathrm{H} 3 . \mathrm{CAR}-\mathrm{BB} \zeta-\mathrm{T}$ s were co-cultured with $\mathrm{B} 7-\mathrm{H}^{+}$ target cells (Figures $4 \mathrm{~J}$ and $\mathrm{S} 2 \mathrm{H}$ ), indicating that B7-H3.CAR$\mathrm{BB} \zeta$-Ts could be less susceptible to PD-L1 mediated inhibition. We stressed the in vitro co-culture conditions by co-culturing B7-H3.CAR-Ts with three PD-L1-negative (Panc-1, Capan-1, and AsPC-1) and two PD-L1-positive (BxPC-3 and Panc-10.05) PDAC cells lines at very low $T$ cell to tumor cell ratio (1 to 10). In these conditions, B7-H3.CAR-BB -Ts showed a trend for better tumor elimination against the two PD-L1+ PDAC tumor cell lines (Figures S2I and S2J). The superior antitumor activity of B7H3.CAR-BBC-Ts versus B7-H3.CAR-28ל-Ts in the presence of $\mathrm{PD}-\mathrm{L} 1$ was more evident in vivo in mice engrafted with the PD-L1+ BxPC-3 tumor cell line (Figures 4K-4M).

\section{B7-H3.CAR-Ts Show Effective Antitumor Activity in} Ovarian Cancer and Neuroblastoma Xenograft Models Since B7-H3 is broadly expressed in multiple solid tumors, we investigated the antitumor effects of B7-H3.CAR-Ts in ovarian cancer (OC) and neuroblastoma (NB) models. Eighteen cryosectioned OC specimens mounted in a tumor microarray (TMA) were analyzed for the expression of $\mathrm{B} 7-\mathrm{H} 3$, and $90 \%$ stained positive with the $376.96 \mathrm{mAb}$ on both tumor cells and stroma (Figures $5 \mathrm{~A}$ and S3A-S3D). Three human OC cell lines (SW626, SK-OV-3, and CaoV-3) that expressed B7-H3 (Figure $5 \mathrm{~B}$ ) were co-cultured with NT, B7-H3.CAR-28\%-Ts or B7-H3.CAR-BB $\zeta-T s$ at T cell to tumor cell ratio of 1 to 5 . As shown in Figures $5 \mathrm{C}-5 \mathrm{E}$, both

(C) Representative ultrasound imaging measurement of the FFluc-Panc-1 tumor on day 50 after tumor implantation in mice treated with CD19.CAR-Ts in the PDAC orthotopic model shown in (A). The arrow indicates the tumor. Dimensions of the tumor were $6.85 \times 5.85 \mathrm{~mm}$.

(D) Bioluminescence kinetics of FFluc-Panc-1 tumor growth (5 mice/group) in the PDAC orthotopic model in (A).

(E) Schema of the PDAC orthotopic xenograft model infused with CAR-Ts on day 28 after tumor inoculation.

( $F$ and $G$ ) Representative bioluminescence images (F) and bioluminescence kinetics $(G)$ of FFluc-Panc- 1 tumor growth (5 mice/group) in the PDAC orthotopic model in (E)

(H) Schema of the PDAC metastatic model.

(I and $\mathrm{J}$ ) Representative bioluminescence images (I) and bioluminescence kinetics ( $\mathrm{J}$ ) of FFluc-Panc-1 cell growth in the PDAC metastatic model (5 mice/group) in (H).

(K) T cells in the blood, spleen, and bone marrow from mice in the PDAC metastatic model in (H) euthanized 70 days after CAR-T infusion were identified by the expression of CD45 and CD3 by flow cytometry (5 mice/group).

Days indicated in $(\mathrm{B}),(\mathrm{F})$, and $(\mathrm{I})$ represent days post T cell infusion. The horizontal bars in $(\mathrm{K})$ represent the mean values. Error bars denote SD; ${ }^{\star \star *} \mathrm{p}<0.0001$, chi-square test. 
A

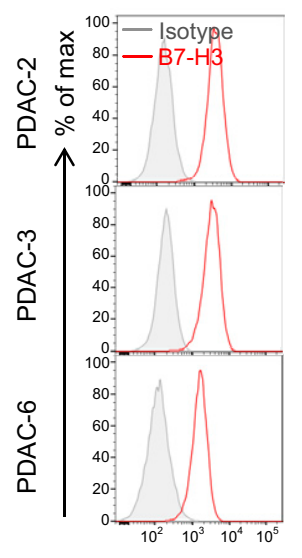

B7-H3 (376.96)
B

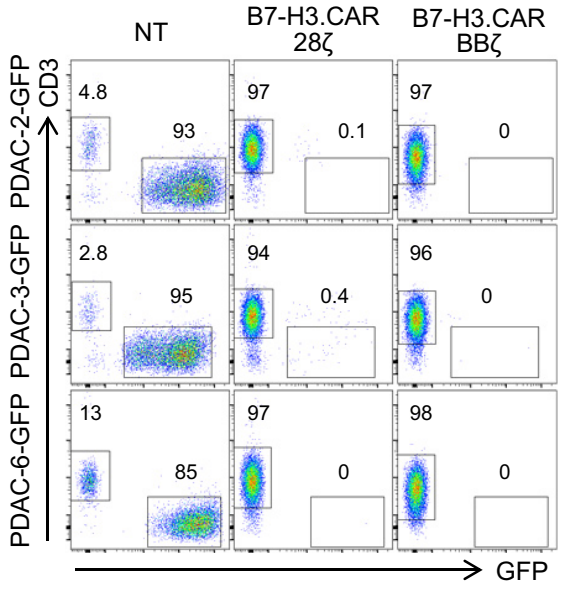

C

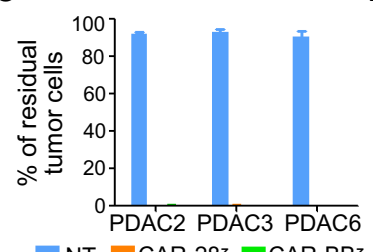

NT $=\mathrm{CAR}-28 \zeta \square \mathrm{CAR}-\mathrm{BB} \zeta$

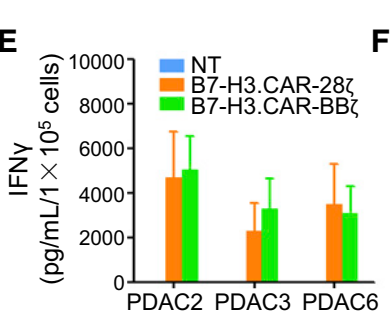

D

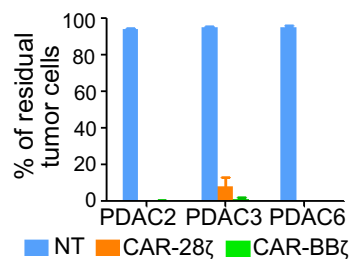

$\mathbf{F}$

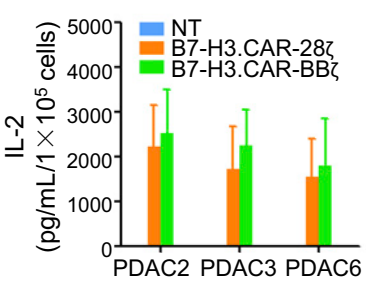

G

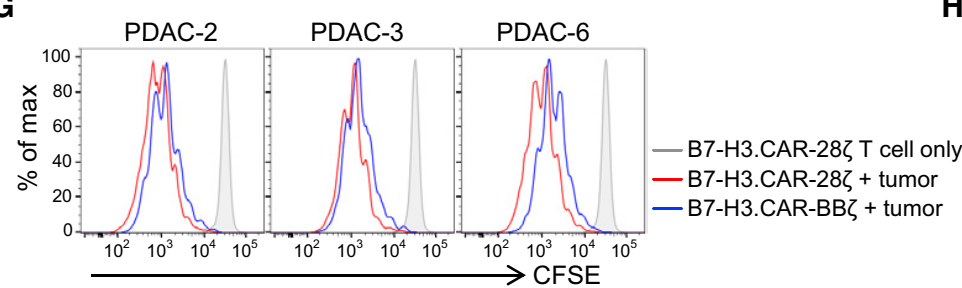

H

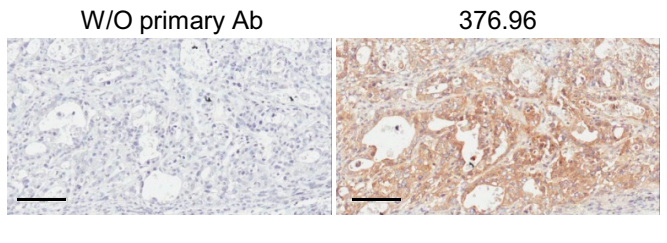

$\mathbf{J}$

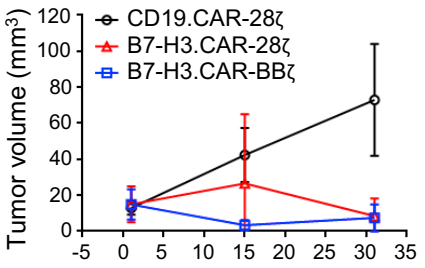

Days post $\mathrm{T}$ cell infusion

K

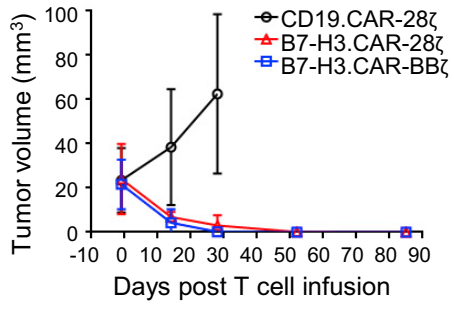

Figure 3. B7-H3.CAR-Ts Target Patient-Derived PDAC In Vitro and In Vivo

(A) Representative flow plots showing B7-H3 expression in early passages of three primary PDAC cell lines established from ascites of three PDAC patients and stained with the $376.96 \mathrm{mAb}$.

(B) The primary PDAC cell lines were labeled with GFP and co-cultured with NT, B7-H3.CAR-28\%-Ts, or B7-H3.CAR-BBל-Ts at the T cell to PDAC ratio of 1 to 5. On day 5 , tumor cells $\left(\mathrm{GFP}^{+}\right)$and $\mathrm{T}$ cells $\left(\mathrm{CD}^{+}\right)$were enumerated by flow cytometry.

( $C$ and D) Summary of residual tumor cells after the co-culture of NT, B7-H3.CAR-28\%-Ts, and B7-H3.CAR-BBל-Ts with the primary PDAC cell lines at T cell to tumor cell ratios of 1 to $5(C)$ (on day $5, n=6$ ) and of 1 to 10 (D) (on day $7, n=4$ ). Error bars denote SD.

( $E$ and F) Summary of IFN- $\gamma(E)$ and IL-2 (F) released in the culture supernatant by NT, B7-H3.CAR-28ל-Ts, and B7-H3.CAR-BBל-Ts after $24 \mathrm{~h}$ of co-culture with the primary PDAC cell lines as measured by ELISA $(n=4)$. Error bars denote SD.

(G) CFSE dilution of CFSE-labeled B7-H3.CAR-28ל-Ts and B7-H3.CAR-BBל-Ts co-cultured with the primary PDAC cell lines for 5 days at 1 to 1 ratio analyzed by flow cytometry. CFSE-labeled T cells alone were used as control.

(H) Representative micrographs of B7-H3 expression in PDAC-PDX engrafted into the pancreas of NSG mice assessed by staining with the $376.96 \mathrm{mAb}$ at the final concentration of $1 \mu \mathrm{g} / \mathrm{mL}$. Slides stained only with the secondary Ab were used as a negative control. Scale bars, $200 \mu \mathrm{m}$.

(I-K) Representative ultrasound images of tumors (dotted circles marked the tumors) (I) and summary of the tumor volumes measured by ultrasound imaging in the first $(\mathrm{J})$ and the second $(\mathrm{K})$ experiment of the PDAC-PDX xenograft model (5 mice/group in each experiment). Error bars denote SD. Scale bars, $5 \mathrm{~mm}$. 
A

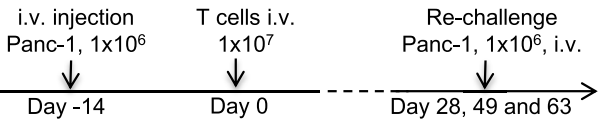

C
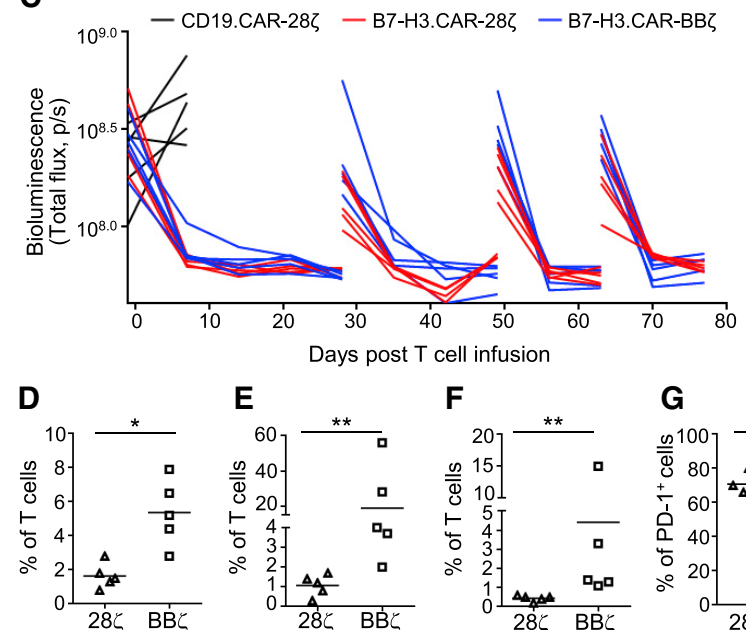

E

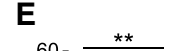

F

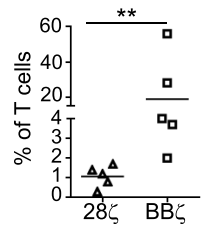

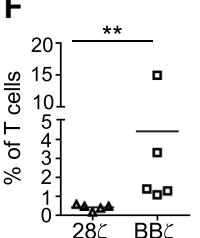

G

$100 \div$

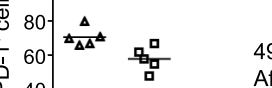

잉 20

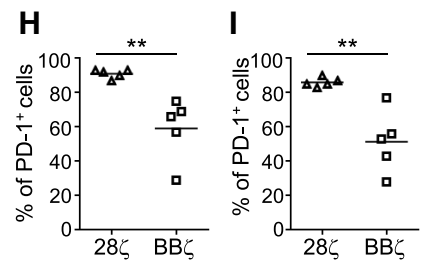

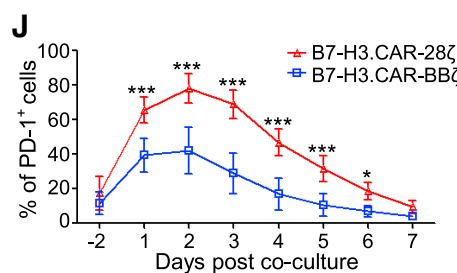

14

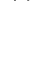

28

28

35

63

\section{3}

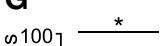

B CD19.CAR-285

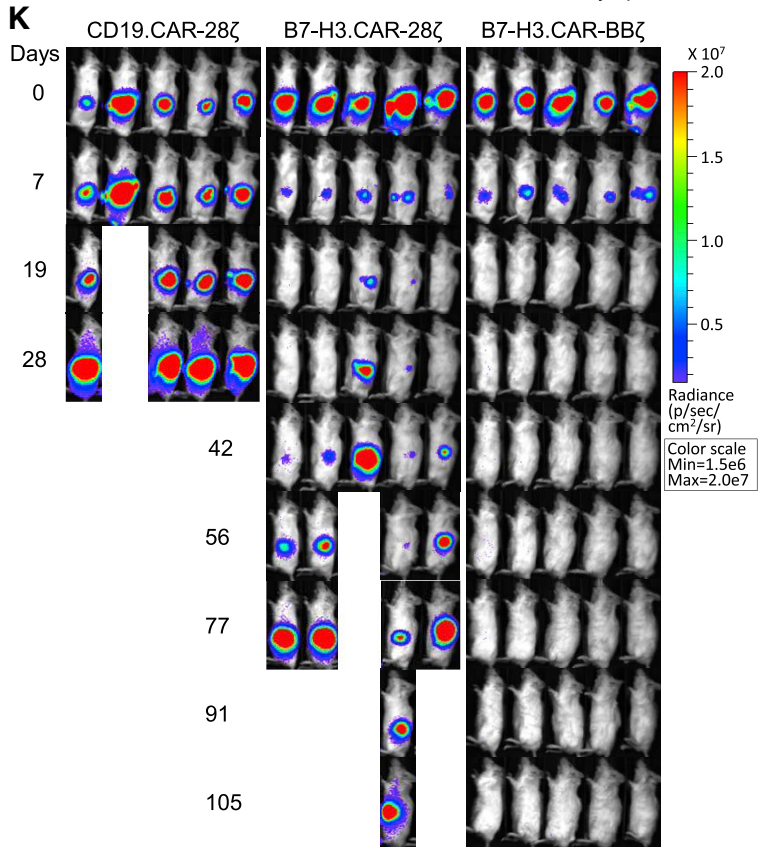

After re-

challenge

49

challenge

56

After re-

challenge

70

B7-H3.CAR-28Z B7-H3.CAR-BBל
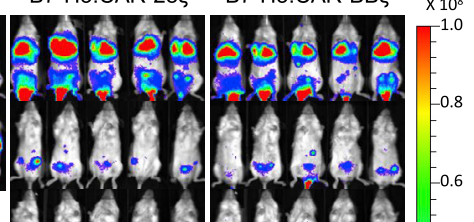

eso a

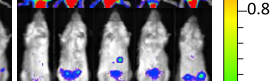

crino

W.

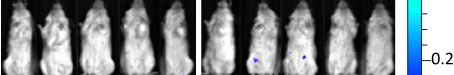

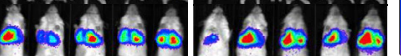

Radiance

Color scale
Min=3es
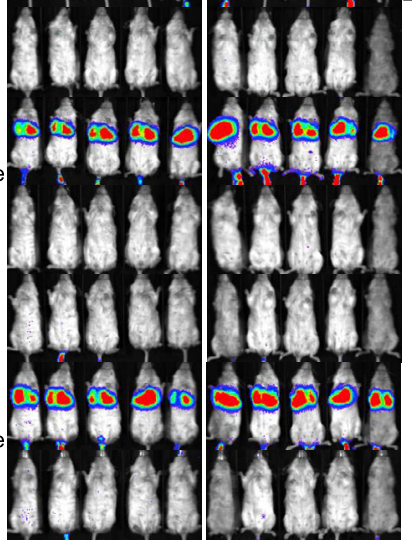

$\mathbf{L}$

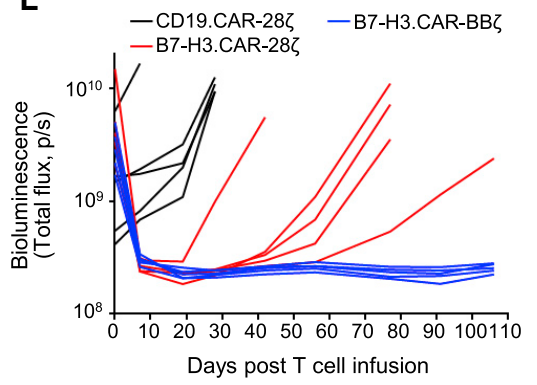

M

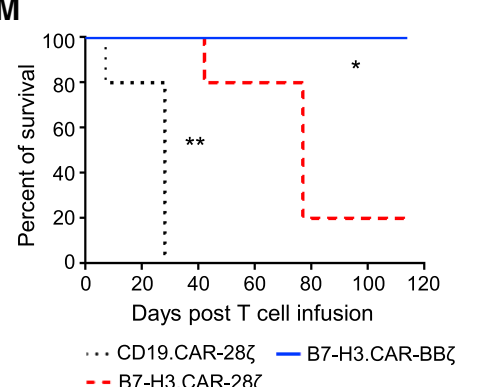

Figure 4. 4-1BB Co-stimulation Promotes Low Expression of PD-1 and Better Antitumor Activity against PDAC Tumor Cells Constitutively Expressing PD-L1

(A) Schema of the Panc-1 tumor rechallenge model in which mice were rechallenged with tumor cells at days 28, 49 , and 63 after CAR-Ts infusion.

( $B$ and $C$ ) Representative bioluminescence images $(B)$ and bioluminescence kinetics $(C)$ of the FFluc-Panc-1 tumor growth in the model shown in (A) (5 mice/group). 
B7-H3.CAR-28ל-Ts and B7-H3.CAR-BBל-Ts effectively controlled the growth of $\mathrm{OC}$ cell lines and released cytokines in the culture supernatant. For the in vivo validation, the FFluctransduced SK-OV-3 tumor cell line was inoculated intraperitoneally (i.p.) into NSG mice to create an i.p. OC model. Two weeks after tumor injection, mice received CD19.CAR-Ts, B7-H3.CAR$28 \zeta-T s$, or B7-H3.CAR-BBל-Ts i.p. since this type of CAR-T delivery is currently considered in clinical trials (NCT02498912). As shown in Figures 5F-5H, B7-H3.CAR-Ts significantly controlled tumor growth and extended the overall survival. Antitumor activity of B7-H3.CAR-Ts was also observed when T cells were infused i.v. (Figures S3E-S3G), although the i.p. inoculation was more effective.

We then assessed the effects of B7-H3.CAR-Ts in NB. The cryosectioned human NB sample positively stained with the 376.96 mAb, as did four human NB cell lines (CHLA-255, IMR32, LAN-1, and SKNLP) (Figures $5 \mathrm{I}$ and $5 \mathrm{~J}$ ). NB tumor cell lines were co-cultured with NT, B7-H3.CAR-28ל-Ts, or B7-H3.CAR$\mathrm{BB} \zeta-\mathrm{T}$ s at $\mathrm{T}$ cell to tumor cell ratio of 1 to 5 . As shown in Figure 5K, B7-H3.CAR-Ts effectively controlled tumor cell growth. Cytolytic activity was corroborated by cytokine release in the co-culture supernatant (Figures $5 \mathrm{~L}$ and $5 \mathrm{M}$ ). FFluc-transduced CHLA-255 tumor cells were infused i.v. into NSG mice to generate a metastatic NB model. To assess the dose effect of B7-H3.CAR-Ts, we infused two different doses of B7H3.CAR-28 $\zeta$-Ts $\left(2 \times 10^{6}\right.$ and $5 \times 10^{6}$ cells/mouse $)$ i.v. 2 weeks after tumor inoculation. B7-H3.CAR-28 3 -Ts controlled tumor growth compared with mice treated with CD19.CAR-Ts, and the highest dose of $T$ cells eliminated the tumor for more than 90 days (Figures $5 \mathrm{~N}-5 \mathrm{P}$ ).

\section{B7-H3.CAR-Ts Control Tumor Growth in} Immunocompetent Mice without Causing Toxicity We assessed the expression of $\mathrm{B} 7-\mathrm{H} 3$ in cryosectioned normal human TMA using the $376.96 \mathrm{mAb}$ from which the B7-H3.CAR was derived. Slides were analyzed blindly by an experienced pathologist (K.G.). Major organs such as heart, brain, lung, kidney, and muscle are B7-H3 negative, while focal, weak to moderate B7-H3-positive staining was observed in the cytoplasm of some normal human tissues (Figure 6 and Table S1). The highest expression was observed in the stomach, with moderate to strong staining of gastric epithelium, adrenal gland with weak to moderate cytoplasmic staining, and salivary gland with moderate to strong cytoplasmic staining of acinar epithelium. To develop a murine model to assess the potential toxicity of B7-H3.CAR-Ts, we evaluated whether the 376.96 mAb cross-reacts with murine B7-H3 (mB7-H3). As shown in Figure S4A, human Raji cells engineered to express $\mathrm{mB} 7-\mathrm{H} 3$ were positively stained by the $376.96 \mathrm{mAb}$, indicating cross-recognition of
mB7-H3 by the 376.96 mAb. mB7-H3 expressing Raji cells were eliminated by B7-H3.CAR-Ts and CD19.CAR-Ts in co-culture experiments (Figures S4B and S4C). In addition, B7H3.CAR-Ts and CD19.CAR-Ts released a comparable level of IFN- $\gamma$ and IL-2 (Figures S4D and S4E), which demonstrates that B7-H3.CAR-Ts and CD19.CAR-Ts show similar activation when targeting $\mathrm{mB} 7-\mathrm{H} 3$ expressing Raji cells. We also measured directly the binding affinity of the $376.96 \mathrm{mAb}$ to both human and murine B7-H3 proteins (Figures S4F and S4G). Even if the binding affinity to $\mathrm{mB} 7-\mathrm{H} 3$ is lower compared with h2lg-B7-H3, which is the human isoform closest to mB7-H3, B7-H3.CAR-Ts still released a significant amount of IFN- $\gamma$ in response to $50 \mathrm{nM}$ of $\mathrm{mB} 7-\mathrm{H} 3$ protein (Figure $\mathrm{S} 4 \mathrm{H}$ ), indicating that an immunocompetent murine model may be informative concerning potential toxic effects of B7-H3.CAR-Ts. We generated a murine version of the B7-H3.CAR by using the same scFv derived from the 376.96 $\mathrm{mAb}$ and replacing human signaling molecules with the murine $\mathrm{CD} 28$ and $\mathrm{CD} 3 \zeta$ (mB7-H3.CAR) (Figure S4I). Activated murine $T$ cells were then transduced with this vector to express the CARs (Figures S4J-S4L). A murine version of the mCD19-specific CAR was used as a control (mCD19.CAR) (Kochenderfer et al., 2010). mB7-H3.CAR-Ts specifically targeted the murine PDAC cell line KPC-4662 engineered to express mB7-H3 (Figures 7A-7D), and released cytokines (Figures $7 \mathrm{E}$ and $7 \mathrm{~F}$ ). To ensure that the $376.96 \mathrm{mAb}$ cross-reacts with the $\mathrm{mB} 7-\mathrm{H} 3$ endogenously expressed by murine cells, we evaluated the expression of $\mathrm{B} 7-\mathrm{H} 3$ in bone marrow-derived dendritic cells (BMDCs) generated from C57BL/6J mice (Lee et al., 2017; Prasad et al., 2004). While non-activated BMDCs had undetectable B7-H3 expression, activation with lipopolysaccharide (LPS) induced $\mathrm{B} 7-\mathrm{H} 3$ expression that was detected at comparable levels when the cells were stained with either the $376.96 \mathrm{mAb}$ or another murine specific B7-H3 mAb (Seaman et al., 2017) (Figure 7G). To test whether LPS-activated BMDCs are targetable by mB7-H3.CAR-Ts, we co-cultured LPS-activated BMDCs with syngeneic NT, mCD19.CAR-Ts or mB-H3.CAR-Ts at 1 to 1 ratio. As shown in Figure $7 \mathrm{H}$, we observed very low or undetectable IFN- $\gamma$ release by $m B 7-H 3$.CAR-Ts in response to activated BMDCs. We also assessed the expression of $\mathrm{mB} 7-\mathrm{H} 3$ in normal murine tissues and observed a similar distribution of $\mathrm{B} 7-\mathrm{H} 3$ as in human tissues (Figure S5 and Table S2). To investigate the potential toxicities of mB7-H3.CAR-Ts in immunocompetent mice, we irradiated non-tumor-bearing 6-week-old C57BL/6J mice with 400 cGy, to create a lymphodepleted environment that favors the expansion of adoptively transferred T cells, and then infused them i.v. with syngeneic control NT, mCD19.CARTs, or mB7-H3.CAR-Ts 2 days later. Five days after $T$ cell infusion, mice receiving mCD19.CAR-Ts showed B cell depletion while no significant changes in blood cell counts and

(D-I) Circulating CAR-Ts $\left(C D 45^{+} \mathrm{CD}^{+}\right)(\mathrm{D}-\mathrm{F})$ and PD-1 expression in CAR-Ts (G-I) in mice 22 days (D and G), 48 days (E and H), and 63 days (F and I) after CAR-Ts infusion were examined by flow cytometry $(n=5) .{ }^{*} p<0.05,{ }^{\star *} p<0.01$, unpaired and non-parametric Mann-Whitney test with two-tailed $p$ value calculation.

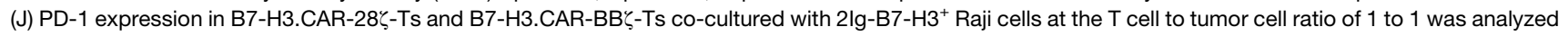
daily from day 1 to day $7(n=8)$. Error bars denote $S D ;{ }^{*} p<0.05,{ }^{* * *} p<0.001$, unpaired and non-parametric Mann-Whitney test with two-tailed $p$ value calculation. ( $K$ and L) NSG mice were engrafted with the FFluc-BxPC-3 PDAC tumor cell line that constitutively expresses PD-L1 and infused with CAR-Ts on day 14 after tumor inoculation. Representative bioluminescence $(\mathrm{K})$ and bioluminescence kinetics $(\mathrm{L})$ of the FFluc-BxPC-3 PDAC tumor cell line (5 mice/group).

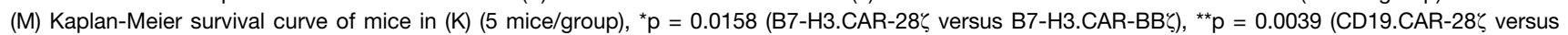
B7-H3.CAR-28ל), chi-square test. In this model for the survival curve, mice were censored when the luciferase signal reached $3.5 \times 10^{9}$ photons per second. Days indicated in $(B)$ and $(K)$ represent the days post T cell infusion. The horizontal bars in (D) to (I) represent the mean values. See also Figure S2. 
A
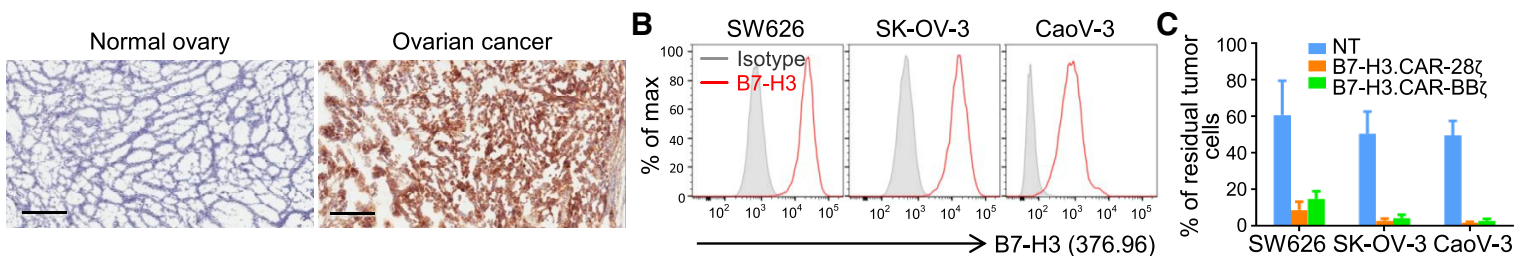

D

E
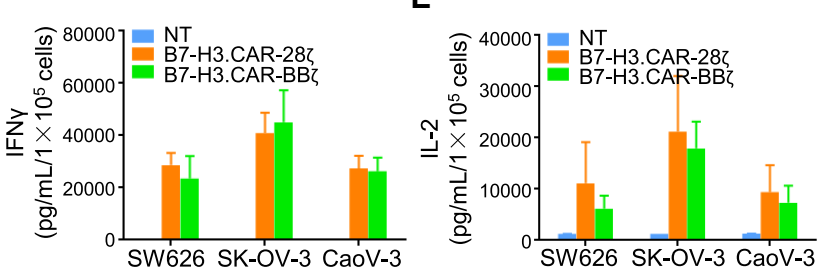

$\mathbf{F}$

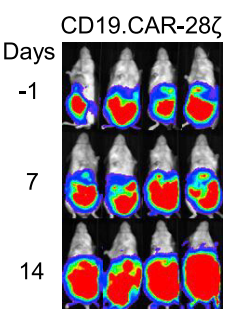

G

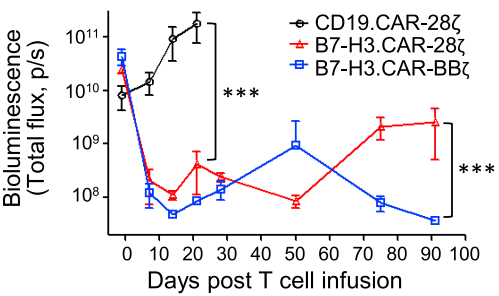

H

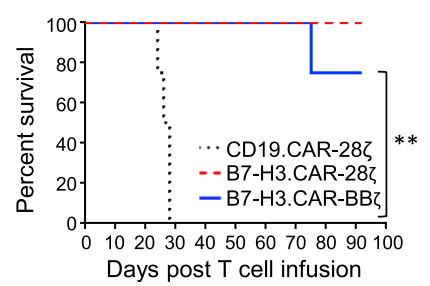

28
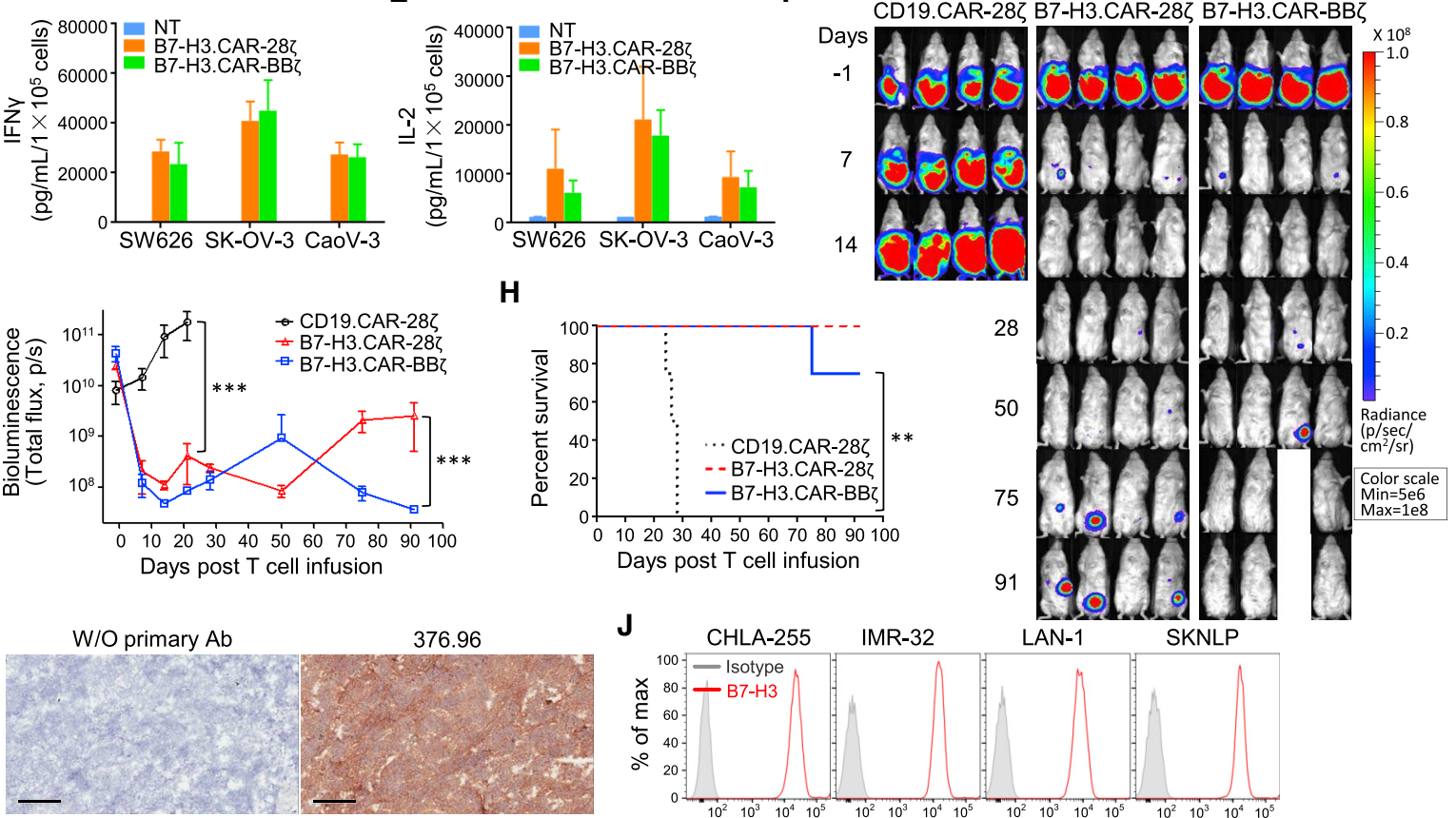

J

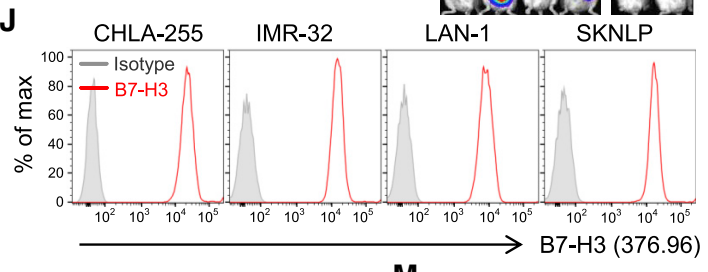

K

L

M
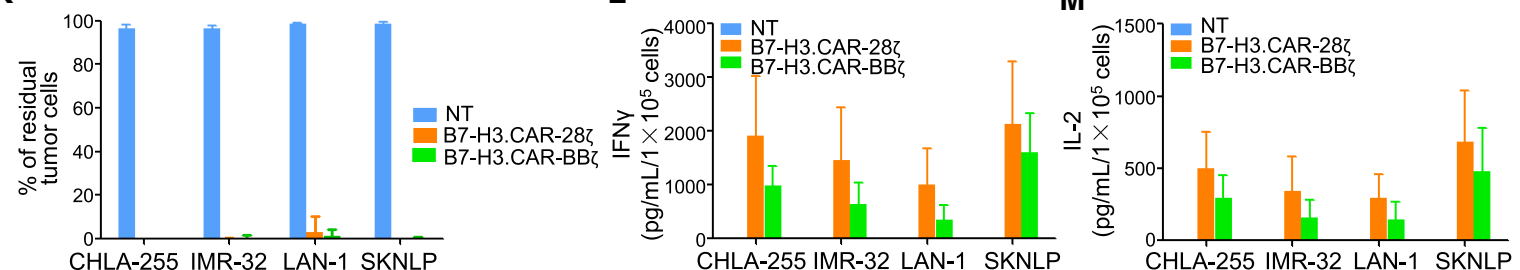

N

B7-H3.CAR-283
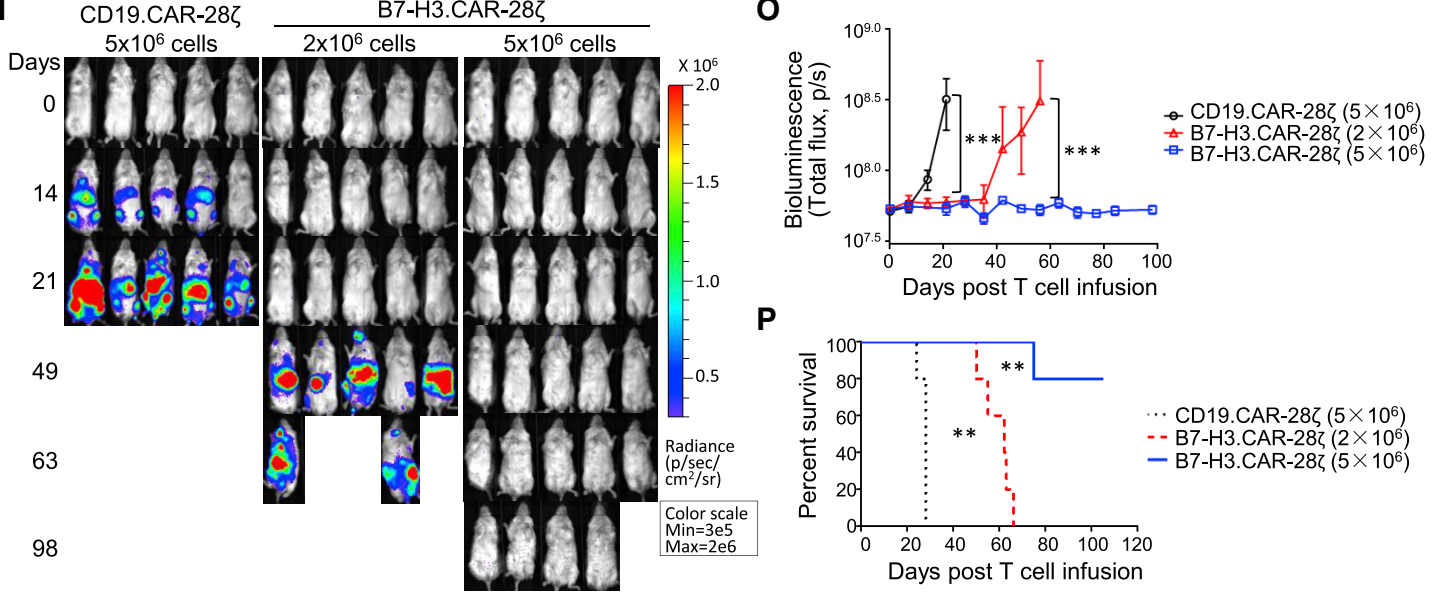

$\mathbf{P}$

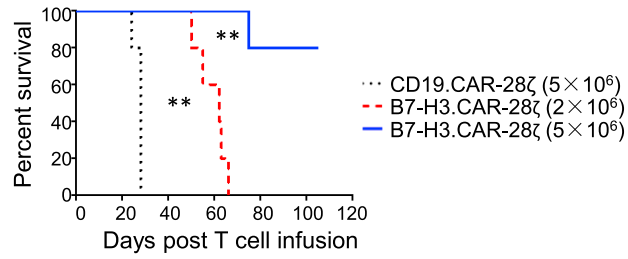

Figure 5. B7-H3.CAR-Ts Target B7-H3 ${ }^{+} \mathrm{OC}$ and NB Cancer Cells Both In Vitro and In Vivo

(A) Representative micrographs of B7-H3 expression in normal ovary and $\mathrm{OC}$ assessed by staining with the $376.96 \mathrm{mAb}$ at the final concentration of $1 \mu \mathrm{g} / \mathrm{mL}$. Scale bars, $200 \mu \mathrm{m}$. 
composition were observed in mice receiving mB7-H3.CAR-Ts (Figures S6A and S6B). As clinical studies with adoptive transfer of CAR-Ts suggest that the maximal expansion mediated by CD28 co-stimulation and potentially lethal toxic effects occur within 2-3 weeks post T cell infusion (Brentjens et al., 2013), mice were monitored for the ensuing 2 weeks and then euthanized to assess organ toxicities. At the time of euthanasia, all mice were alive and healthy. Mice treated with mCD19.CAR-Ts showed persistent B cell depletion in blood, spleen, and bone marrow while mice treated with mB7-H3.CAR-Ts did not show any decrease in cell counts (Figures $7 \mathrm{I}-7 \mathrm{~K}$ ). Similarly, no evident lesions or aberrant $\mathrm{T}$ lymphocyte infiltration were observed in tissue sections (Figure S7 and Table S3). To rule out any effect due to the irradiation of the mice before the infusion of CAR-Ts, we also infused C57BL/6J mice with mB7-H3.CAR-Ts without irradiation. Mice euthanized and analyzed at day 11 after T cell infusion did not show evident signs of toxicity (Figures S6C-S6E). We further evaluated the effects of mB7-H3.CAR-Ts in tumorbearing mice. In brief, 6-week-old C57BL/6J mice were orthotopically engrafted in the pancreas with the murine PDAC tumor cell line KPC-4662 modified to express mB7-H3. Seventeen days later, mice were irradiated with $400 \mathrm{cGy}$ and then infused i.v. with syngeneic control NT or mB7-H3.CAR-Ts 2 days later (Figure 8A). As shown in Figures 8B and 8C, mB7-H3.CAR-Ts controlled tumor growth for 4 weeks as assessed by ultrasound measurement and tumor weight. When euthanized at days $33-$ 34,2 of 5 control mice showed liver metastases in addition to the primary pancreatic tumor, while liver metastases were not observed in mB7-H3.CAR-Ts-treated mice. At the time of euthanasia, in mice with tumor we did observe a slight increase of T cell infiltration and PD-1 expression at the tumor site in $\mathrm{mB} 7-$ H3.CAR-Ts-treated group compared with control mice (Figures S8A-S8D). The molecular signal of $\mathrm{mB} 7-\mathrm{H} 3$.CAR was detectable in the spleen and tumor collected from mB7-H3.CAR-Ts-treated mice but not in control mice (Figures $8 \mathrm{D}$ and $8 \mathrm{E}$ ). Mice treated with mB7-H3.CAR-Ts did not show any significant decrease of hematopoietic cell or immune cell counts in blood, spleen, bone marrow, and lymph nodes, except for the decrease in monocyte counts in the peripheral blood (Figures 8F, 8G, S8E, and S8F), and no evident lesions were observed in tissue sections (Figures $8 \mathrm{H}$ and S8G; Table S4). Overall, these results indicate that B7-H3.CAR-Ts promote tumor control in tumorbearing $\mathrm{C} 57 \mathrm{BL} / 6 \mathrm{~J}$ mice without causing detectable organ toxicity.

\section{DISCUSSION}

We investigated whether $\mathrm{B} 7-\mathrm{H} 3$ is a clinically relevant target for CAR-T-based immunotherapy in solid tumors. We found that $\mathrm{B} 7-\mathrm{H} 3$ is aberrantly expressed on the cell surface of PDAC, $\mathrm{OC}$, and NB, and that B7-H3.CAR-Ts effectively controlled tumor growth in orthotopic and metastatic xenografts and in PDAC-PDX models. The observed murine-human cross-reactivity of the 376.96 mAb from which the B7-H3.CAR was derived also allowed us to test the efficacy and safety of B7-H3.CAR-Ts in an immunocompetent mouse model.

The selection of appropriate target antigens in solid tumors remains challenging for the therapeutic development of safe and effective CAR-T-based therapies. Toxicities upon the infusion of CAR-Ts were observed when targeting molecules such as HER2 or CAIX as these molecules are expressed in some normal tissues (Lamers et al., 2013, 2016; Morgan et al., 2010). On the other hand, the therapeutic activity of CAR-Ts can be limited due to the rapid tumor escape when the targeted antigen shows heterogeneous expression within the tumor, as recently reported in patients with glioblastoma treated with CAR-Ts specific for EGFRvIII (O'Rourke et al., 2017). While the intratumor heterogenic expression of the targeted antigen can potentially be resolved by targeting multiple antigens, toxicities related to recognition of antigen expressed by normal tissues remains a major concern. Increasing evidence suggests that intrinsic characteristics of CAR molecules, such as the epitope recognized by the CAR and the affinity of the mAb from which the CAR is derived, may play a significant role in discriminating antigen recognition in normal versus malignant cells. For instance, two clinical studies targeting HER2 with CAR-Ts derived from two distinct mAbs showed different safety profiles (Ahmed et al., 2015, 2017; Morgan et al., 2010). Similarly, different mAbs

(B) Expression of B7-H3 in three human OC cell lines assessed by flow cytometry after staining with the 376.96 mAb.

(C) Summary of residual tumor cells in the culture on day 5 of co-culture of NT, B7-H3.CAR-28 $3-T s$, and B7-H3.CAR-BB $\zeta-T s$ with OC cell lines at T cell to tumor cell ratio of 1 to $5(n=5)$. Error bars denote SD.

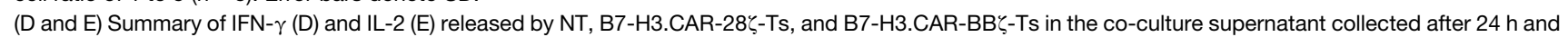
measured by ELISA $(n=5)$. Error bars denote SD.

( $F$ and G) Representative bioluminescence images $(F)$ and bioluminescence kinetics $(\mathrm{G})$ of FFluc-SK-OV-3 tumor growth upon intraperitoneal (i.p.) inoculation into NSG mice $\left(5 \times 10^{5}\right.$ cells/mouse) and treatment 14 days later with i.p. inoculation of CD19.CAR-Ts, B7-H3.CAR-28 $3-T s$, and B7-H3.CAR-BB $\zeta-T s ~\left(5 \times 10^{6}\right.$ cells/ mouse). Error bars denote SD; ${ }^{\star * *} \mathrm{p}<0.0001$, chi-square test.

(H) Kaplan-Meier survival curve of mice developing OC (5 mice/group). ${ }^{\star *} p=0.0091$, chi-square test.

(I) Representative micrographs of B7-H3 expression in NB assessed by staining with the $376.96 \mathrm{mAb}$ at the final concentration of $1 \mu \mathrm{g} / \mathrm{mL}$. Scale bars, $200 \mu \mathrm{m}$. (J) Expression of B7-H3 in human NB tumor cell lines stained with the 376.96 mAb and assessed by flow cytometry.

(K) Summary of residual tumor cells in the culture on day 5 of co-culture of NT, B7-H3.CAR-28ל-Ts, and B7-H3.CAR-BB $\zeta-T s$ with NB tumor cell lines at T cell to tumor cell ratio of 1 to $5(n=8)$. Error bars denote SD.

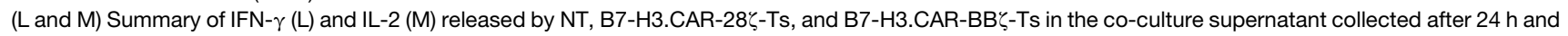
measured by ELISA $(n=8)$. Error bars denote SD.

( $\mathrm{N}$ and $\mathrm{O})$ Representative bioluminescence images $(\mathrm{N})$ and kinetics of the bioluminescence (O) of the FFluc-CHLA-255 tumor growth upon intravenous (i.v.) injection into NSG mice $\left(2 \times 10^{6}\right.$ cells/mouse $)$ and i.v. infusion with CD19.CAR-Ts $\left(5 \times 10^{6}\right.$ cells/mouse $)$ or B7-H3.CAR-28 $3-T s\left(2 \times 10^{6}\right.$ or $5 \times 10^{6}$ cells/mouse $)$ 14 days later (5 mice/group). Error bars denote $S D ;{ }^{* \star *} \mathrm{p}<0.0001$, chi-square test.

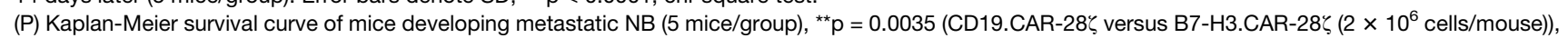
${ }^{* *} \mathrm{p}=0.0018\left(\mathrm{~B} 7-\mathrm{H} 3 . \mathrm{CAR}-28 \zeta 2 \times 10^{6}\right.$ versus $\left.5 \times 10^{6} \mathrm{cells} / \mathrm{mouse}\right)$, chi-square test.

Days indicated in $(F)$ and $(N)$ represent the days post T cell infusion. See also Figure S3. 
A

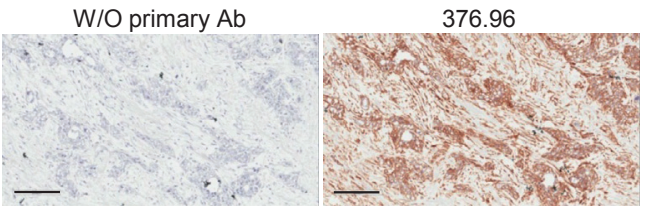

B
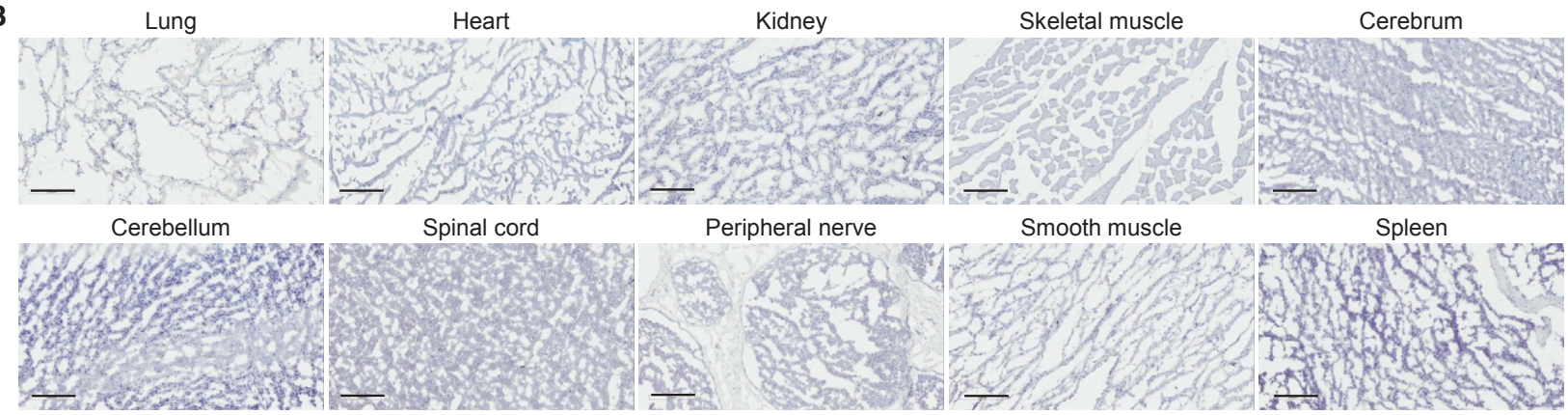

Spinal cord

Peripheral nerve

Smooth muscle

Spleen
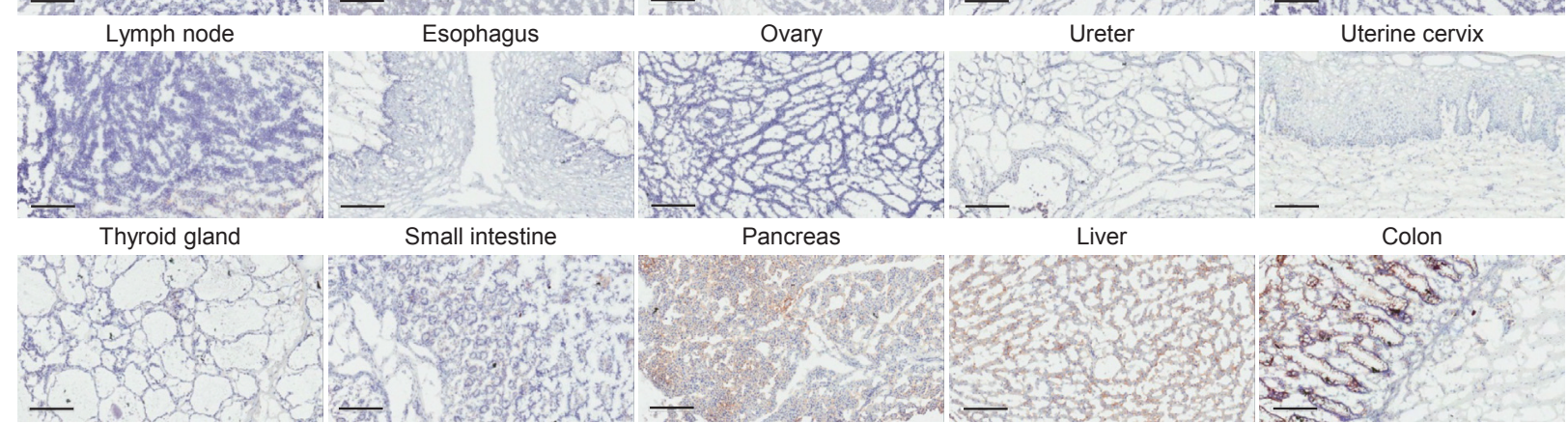

Small intestine
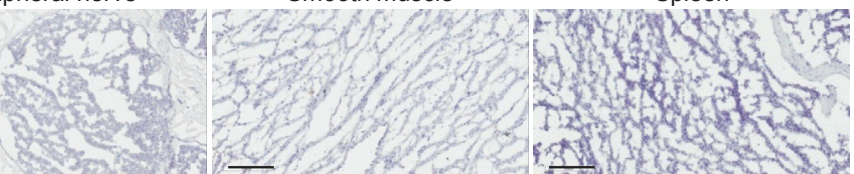

Ovary
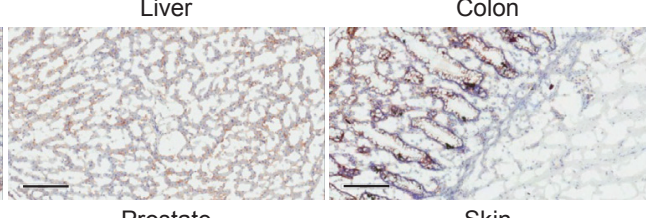

Stomach

Placenta

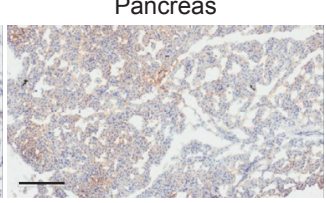

Skin

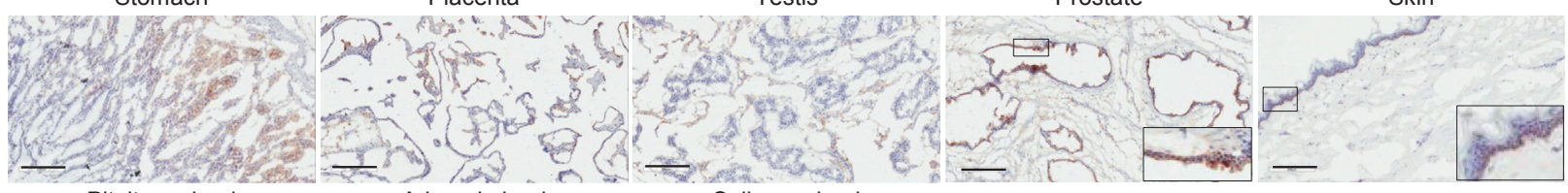

Pituitary gland

Adrenal gland

Salivary gland

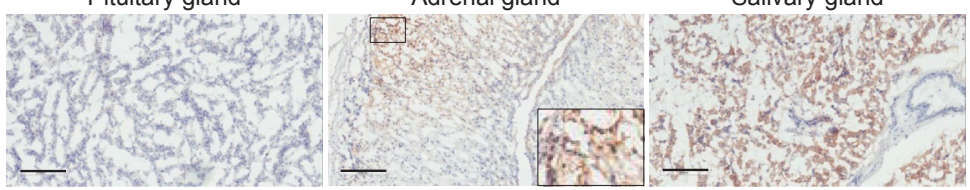

C

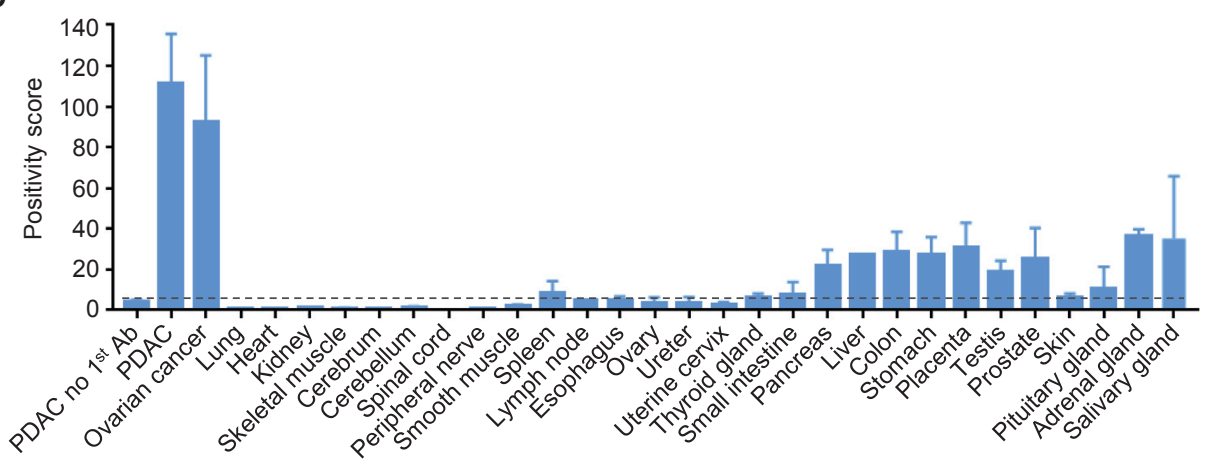

Figure 6. Pattern of B7-H3 Expression in Human Normal Tissues

(A and B) Representative micrographs of B7-H3 expression in PDAC (A) and in indicated normal human organs (B) assessed by staining with the $376.96 \mathrm{mAb}$ at the final concentration of $1 \mu \mathrm{g} / \mathrm{mL}$. Slides stained only with the secondary Ab were used as a negative control. Black boxes indicate 3-fold zoomed-in cutout. Micrographs are representative of at least three sections per tissue. Scale bars, $200 \mu \mathrm{m}$.

(C) Summary of the positive score of B7-H3 in human normal tissues. Dotted line indicates the background level of the staining. Error bars denote SD.

See also Table S1. 
A

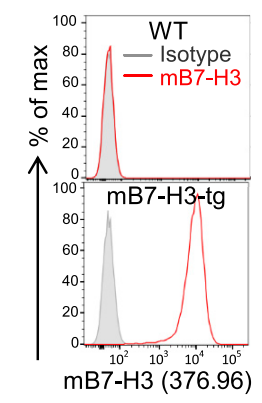

E

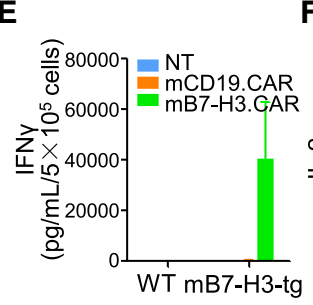

B

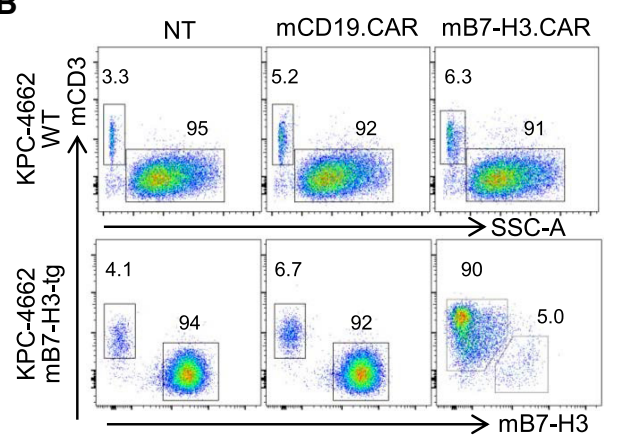

C

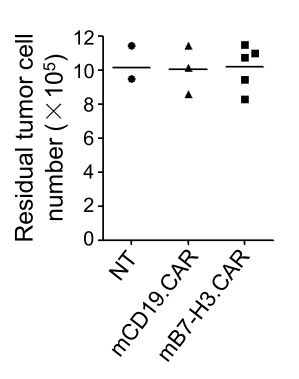

D

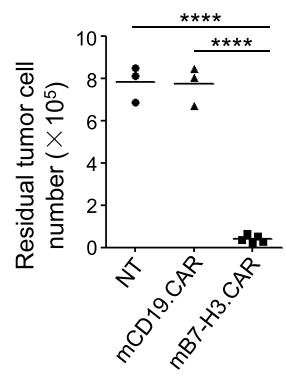

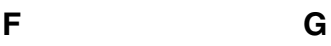

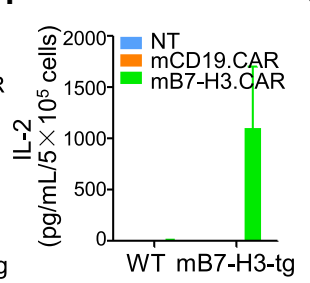

\section{G}

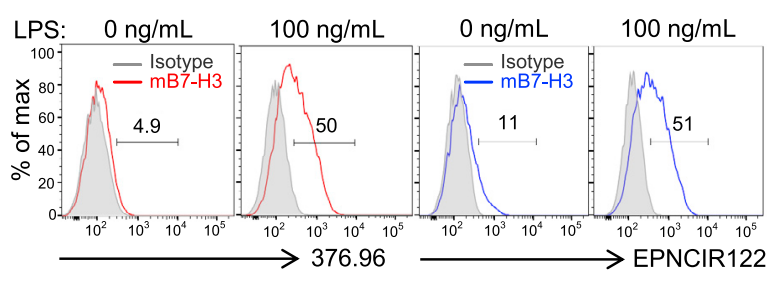

H

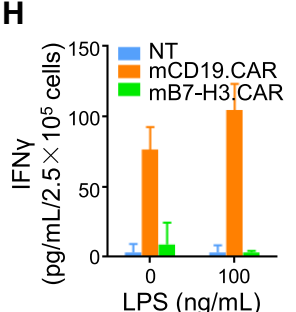

I
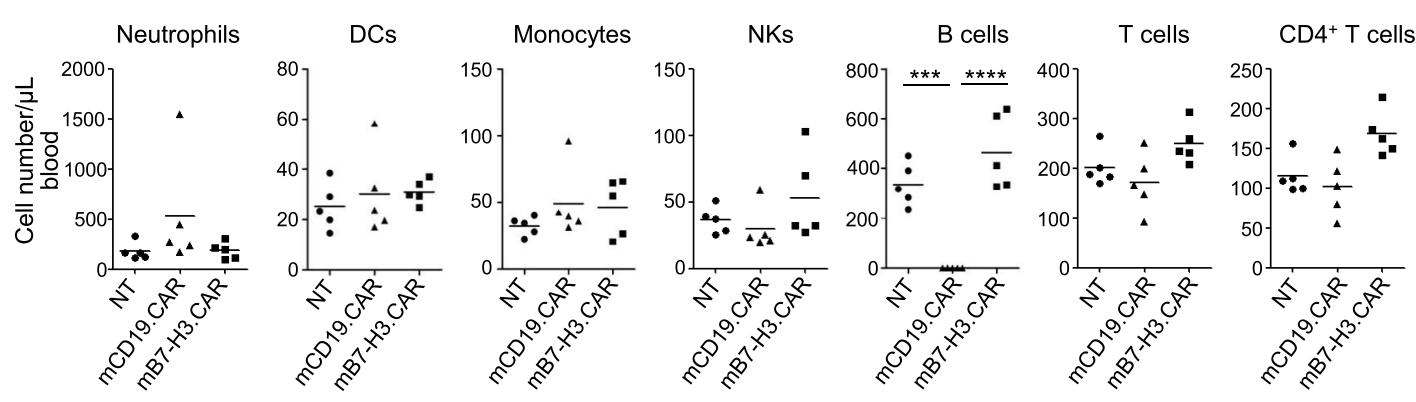

$\mathrm{CD}^{+} \mathrm{T}$ cells

J
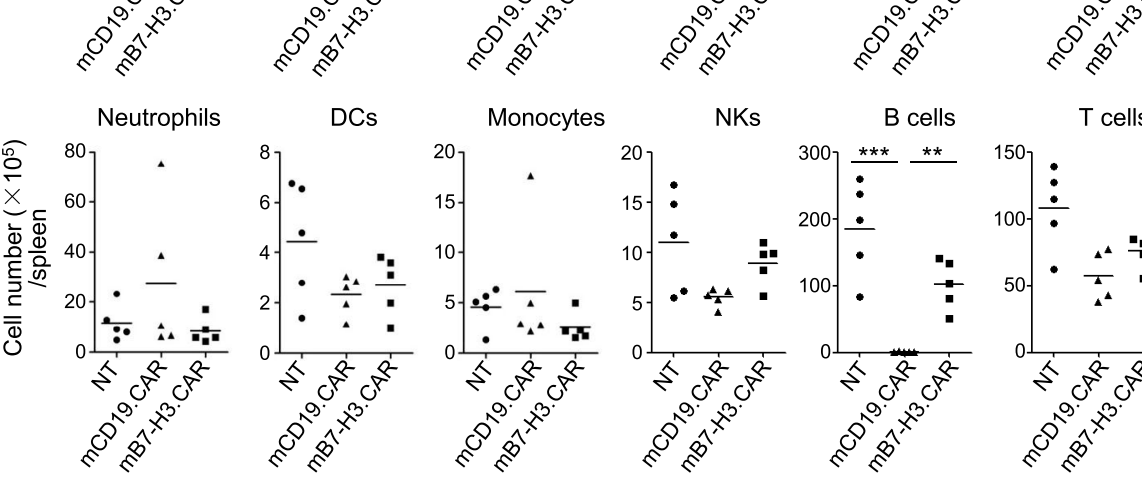

ही

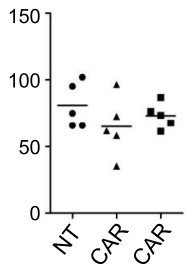

K
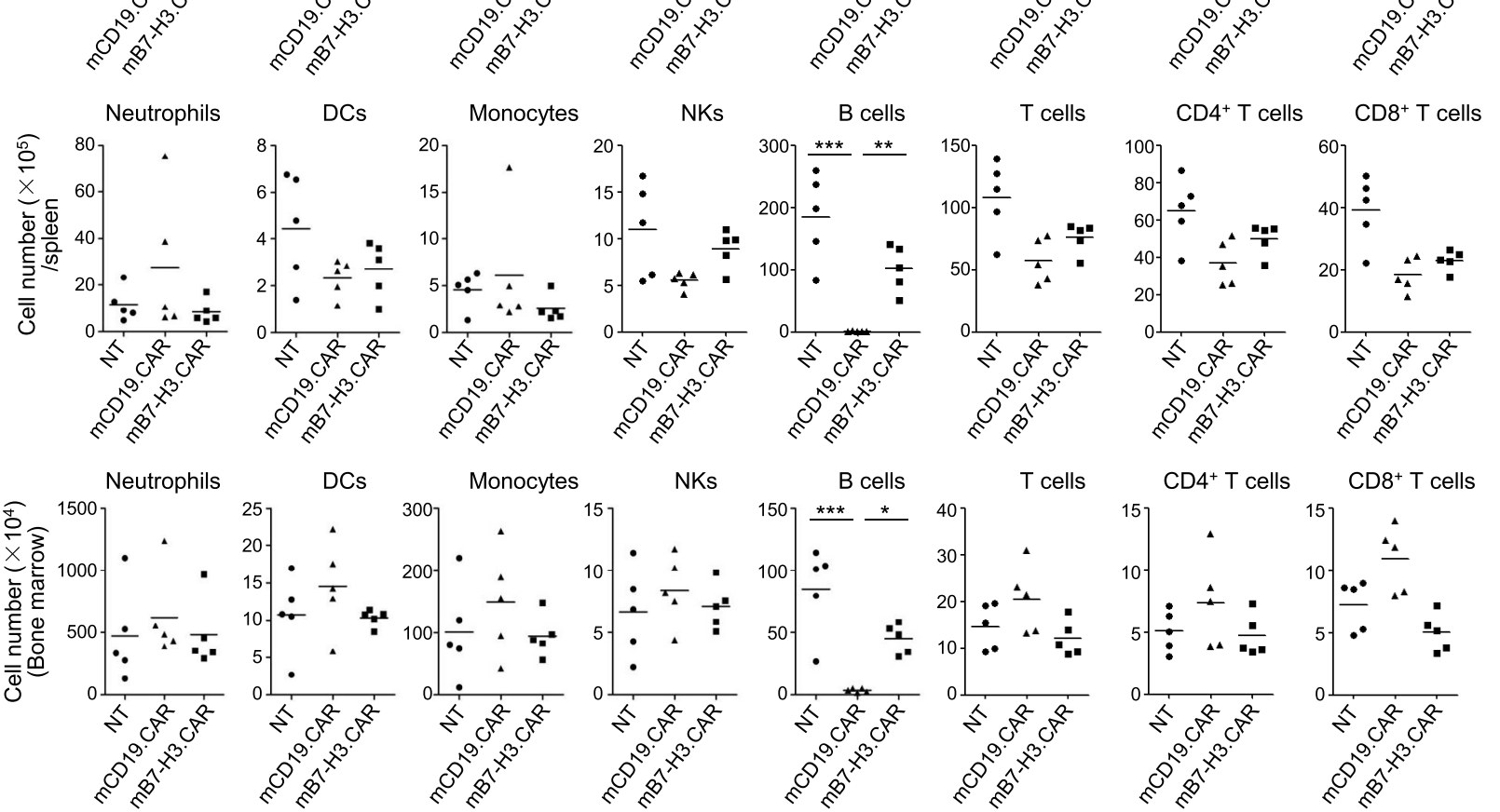
targeting the same ROR1 antigen, another target evaluated for CAR-T-based therapy, showed a different pattern of expression in normal tissues (Balakrishnan et al., 2017; Baskar et al., 2008; Dave et al., 2012).

Targeting B7-H3 with the B7-H3.CAR derived from the $376.96 \mathrm{mAb}$ addresses critical hurdles to the clinical development of CAR-Ts against solid tumors. The 376.96 mAb captures $\mathrm{B} 7-\mathrm{H} 3$ expression in several human malignancies and tumor cell lines, recapitulating the high expression of $\mathrm{B} 7-\mathrm{H} 3$ previously reported in solid tumors (Loos et al., 2010; Picarda et al., 2016). In our experiments, B7-H3.CAR-Ts derived from the 376.96 mAb showed significant antitumor activity in multiple xenografts of solid tumors, indicating the high potential for clinical translation of B7-H3.CAR-Ts if these cells do not cause on-target but off-tumor toxicity. To assess this critical point, we used the $376.96 \mathrm{mAb}$ to stain normal human tissues and observed focal cytoplasmic expression on endothelial cells of normal tissues and areas of high expression in a restricted array of tissues such as stomach, adrenal gland, and salivary gland. Other reports showed a similar pattern of B7-H3 expression in normal tissues using other mAbs (Modak et al., 2001; Seaman et al., 2017). Our immunohistochemistry analysis of normal murine tissues also showed a conserved pattern of B7-H3 expression between human and murine tissues. We took advantage of the observed cross-reactivity of the 376.96 $\mathrm{mAb}$ with murine B7-H3 to perform toxicology and efficacy studies in immunocompetent mice. We have found control of tumor growth without modifications of the immune cell and hematopoietic cell counts with the exception of monocytes in the peripheral blood, and no evidence of tissue damage. Despite the fact that the binding affinity of the $376.96 \mathrm{mAb}$ to $\mathrm{mB} 7-$ $\mathrm{H} 3$ is inferior to the binding affinity of the human $2 \operatorname{lgB} 7-\mathrm{H} 3$, the considerable amount of IFN- $\gamma$ released by B7-H3.CAR-Ts exposed to $50 \mathrm{nM}$ of recombinant $\mathrm{mB} 7-\mathrm{H} 3$ ensures that at least major toxic effects due to B7-H3.CAR-Ts should be captured in immunocompetent mice. Our observed lack of on-target off-tumor toxicity of B7-H3.CAR-Ts in immunocompetent mice may be due to the lower density of $\mathrm{mB} 7-\mathrm{H} 3$ in normal tissues compared with tumor cells, as illustrated in our experiments using clones expressing different levels of human $\mathrm{B} 7-\mathrm{H} 3$ and in murine BMDCs, and as previously reported for other CARs (Walker et al., 2017). Consistent with our observation, the B7H3-specific pyrrolobenzodiazepine-linked m276 mAb showed antitumor activity in xenograft mouse models targeting both tumor cells and tumor-associated vasculatures, without overt toxicity (Fauci et al., 2014; Loo et al., 2012; Seaman et al., 2017). Although a different expression profile of $B 7-H 3$ in mu- rine and human normal tissues remains a possibility, toxicology studies of an Fc-enhanced B7-H3 Ab carried out in cynomolgus monkeys also revealed no significant toxicities (Loo et al., 2012). Furthermore, in a clinical study in which the ${ }^{131}$ I-conjugated $\mathrm{B} 7-\mathrm{H} 3 \mathrm{Ab}$ was administered to patients with metastatic NB, no toxicity was encountered (Kramer et al., 2010). Finally, the clinical translation of B7-H3.CAR-Ts may be further safely conducted by using either transient expression of the B7H3.CAR in T cells as achieved using mRNA electroporation (Beatty et al., 2014) or by further modifying B7-H3.CAR-Ts to include the inducible caspase- 9 safety switch that provides an extra safeguard ensuring the rapid elimination of CAR-Ts in case of toxicities (Di Stasi et al., 2011; Diaconu et al., 2017).

The optimal co-stimulation for CAR-Ts, especially in solid tumors, remains a matter of significant discussion. It is likely that CAR co-stimulation needs to be adapted to specific target antigens, tumor cell type, and tumor microenvironment. In our study, we systematically compared CD28 with 4-1BB co-stimulation in either orthotopic or metastatic PDAC models. We did not find significant differences at least in our model using the Panc-1 PDAC cancer cell line. In particular, phenotypic analysis in vivo did not show significant differences of effector versus memory $T$ cells in mice treated with B7-H3.CAR-Ts expressing CD28 or 4-1BB. However, 4-1BB co-stimulation preserved $\mathrm{CD}^{+} \mathrm{T}$ cells with lower expression of $\mathrm{PD}-1$ both in vitro and in vivo, and when PDAC cell lines constitutively express

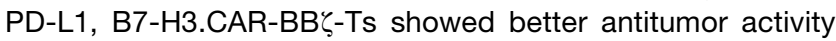
compared with B7-H3.CAR-28ל-Ts. Finally, the desmoplastic nature of solid tumors in general and PDAC in particular impairs trafficking, penetration, and survival of CAR-Ts (Newick et al., 2017). PDAC-PDX tumors are characterized by stroma fibrosis that mirrors the donor tumor (Tentler et al., 2012). We tested B7-H3.CAR-Ts in PDAC-PDX models and found significant antitumor activity, although tumors were not always eradicated. Furthermore, B7-H3.CAR-Ts controlled PDAC tumor growth in immunocompetent mice, but did not eradicate the tumor and showed limited persistence within the tumor, suggesting that the activity of CAR-Ts in solid tumors should be further augmented using additional $\mathrm{T}$ cell engineering and combination with chemotherapy, irradiation, small molecules, or other biological agents (Caruana et al., 2015; Dotti et al., 2014).

In summary, we developed B7-H3.CAR-Ts that control the tumor growth of PDAC, NB, and OC in xenograft models. B7-H3.CAR-Ts did not cause evident toxicity in either NSG or immunocompetent mice, further encouraging their clinical application in solid tumors that are difficult to treat.

(C and D) Summary of residual WT KPC-4662 cells (C) and mB7-H3-Tg KPC-4662 cells (D) in the co-culture experiments in (B) $(n \geq 3) .{ }^{* \star *} p<0.0001$, one-way ANOVA with Holm-Sidak test adjusted $p$ value.

(E and F) IFN- $\gamma(E)$ and IL-2 (F) released by NT, mCD19.CAR-Ts, and B7-H3.CAR-Ts after $24 \mathrm{~h}$ in the co-culture experiments in (B) as measured by ELISA ( $\mathrm{n}=3$ ). Error bars denote SD.

(G) Murine bone marrow-derived dendritic cells (BMDCs) treated without or with $100 \mathrm{ng} / \mathrm{mL}$ LPS for 2 days were stained with the $376.96 \mathrm{mAb}$ or the EPNCIR122 $\mathrm{mAb}$, and the expression of $\mathrm{mB} 7-\mathrm{H} 3$ was assessed by flow cytometry.

(H) IFN- $\gamma$ released by NT, mCD19.CAR-Ts, and mB7-H3.CAR-Ts after $24 \mathrm{~h}$ of co-culture with BMDCs treated without or with $100 \mathrm{ng} / \mathrm{mL}$ LPS for 2 days at T cell to target cell ratio of 1 to 1 as measured by ELISA $(n=3)$. Error bars denote SD.

(I-K) C57BL/6 mice were irradiated with 400 cGy and 2 days later infused i.v. with syngeneic NT, mCD19.CAR-Ts, or mB7-H3.CAR-Ts $\left(1 \times 10^{7}\right.$ cells/mouse). Mice were euthanized $15-16$ days post $T$ cell infusion to analyze the immune cell composition of the blood $(\mathrm{l})$, spleen $(\mathrm{J})$, and bone marrow $(\mathrm{K})$ by flow cytometry $(5$ mice/group). ${ }^{\star} p<0.05,{ }^{\star \star} p<0.01,{ }^{* \star *} p<0.001,{ }^{\star \star \star \star *} p<0.0001$, one-way ANOVA with Holm-Sidak test adjusted $p$ value.

The horizontal bars in (C), (D), and (I) to (K) represent the mean values. See also Figures S4-S7; Tables S2 and S3. 

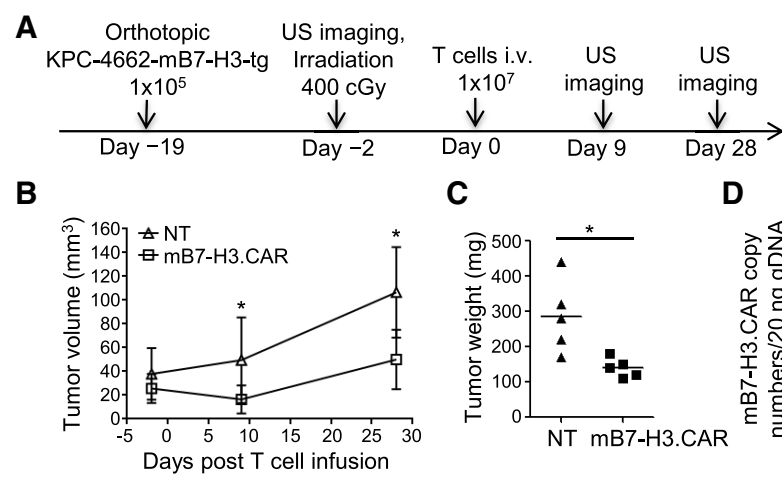

C

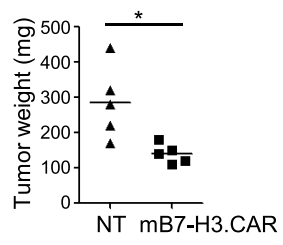

D

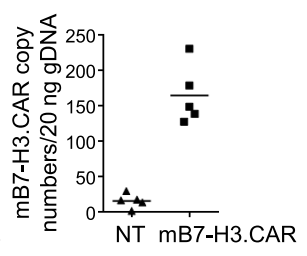

$\mathbf{E}$

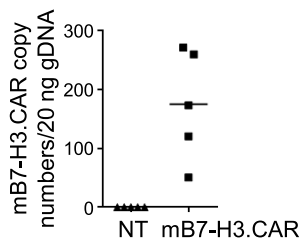

F

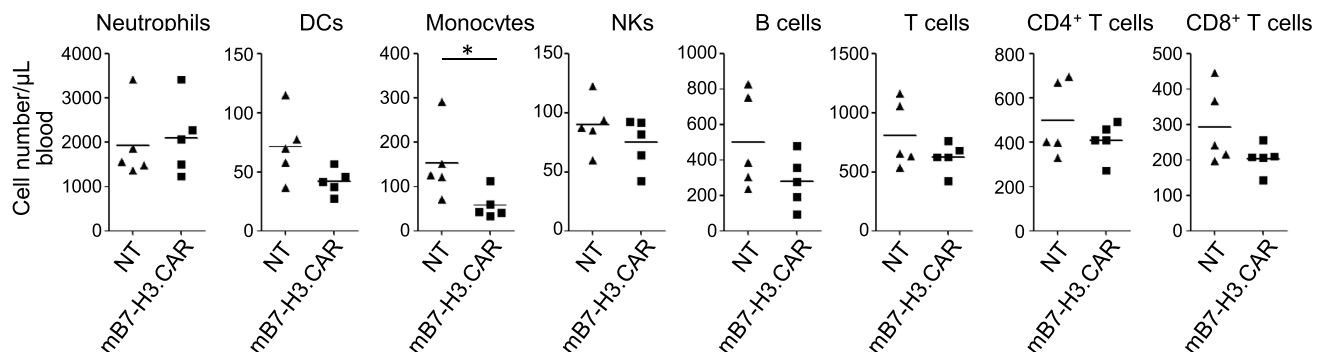

G
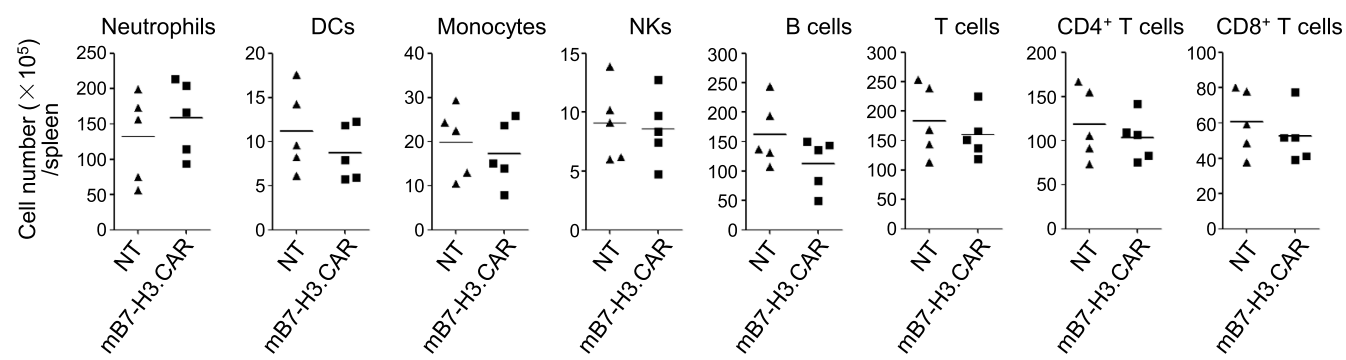

H
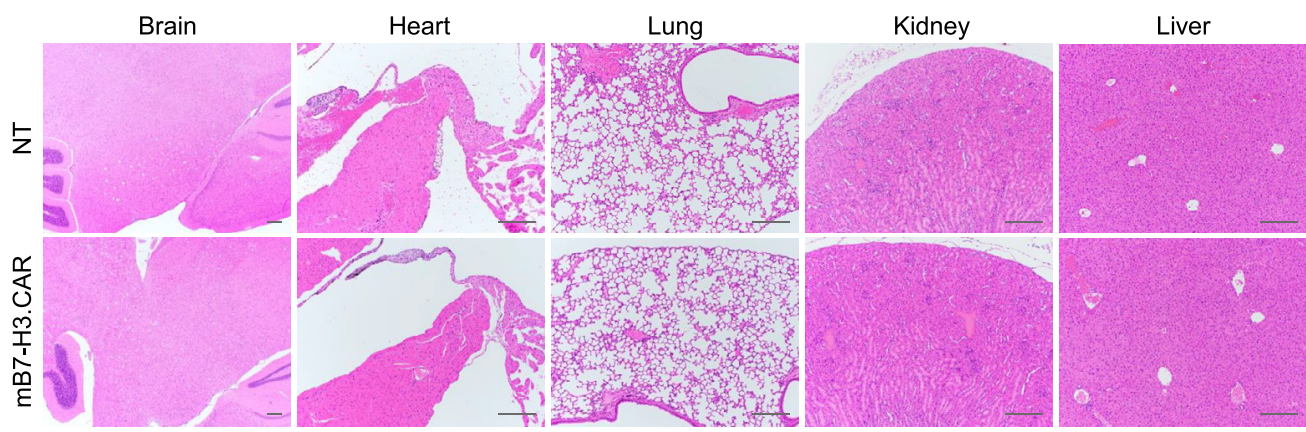

Figure 8. B7-H3.CAR-Ts Control Tumor Growth in Immunocompetent Mice without Causing Evident Toxicity

(A) Schema of the murine PDAC orthotopic xenograft model.

(B) Summary of the tumor volume measured by ultrasound imaging ( $n=5$ per group). Error bars denote SD; ${ }^{*} p=0.0476$ (day 9 ) and ${ }^{*} p=0.0278$ (day 28 ), unpaired and non-parametric Mann-Whitney test with two-tailed $p$ value calculation.

(C) Summary of the tumor weight at the end of the experiment (day $33-34$ after T cell infusion) ( $n=5$ per group). ${ }^{*} \mathrm{p}=0.0157$, unpaired and non-parametric MannWhitney test with two-tailed $\mathrm{p}$ value calculation.

(D and E) Quantification of mB7-H3.CAR copy numbers by qPCR to evaluate CAR-Ts persistence in the spleens (D) and tumors (E) at the end of the experiment (day $33-34$ after $\mathrm{T}$ cell infusion).

( $F$ and $G$ ) Cell subset composition of the blood $(F)$ and spleens $(G)$ was analyzed by flow cytometry ( $n=5$ per group). ${ }^{*} p=0.0159$, unpaired and non-parametric Mann-Whitney test with two-tailed $p$ value calculation.

(H) Tissue pathology of the indicated organs was evaluated by H\&E staining at the end of the experiment (days $33-34$ after T cell infusion). Scale bars, $200 \mu \mathrm{m}$. The horizontal bars in $(C)$ to $(G)$ represent the mean values. See also Figure S8 and Table S4. 


\section{STAR $\star$ METHODS}

Detailed methods are provided in the online version of this paper and include the following:

- KEY RESOURCES TABLE

- CONTACT FOR REAGENT AND RESOURCE SHARING

- EXPERIMENTAL MODEL AND SUBJECT DETAILS

O Cell Lines and Cell Culture

O Human and Mouse Tissue Samples

O In Vivo Mouse Studies

- METHOD DETAILS

O Plasmid Construction and Retrovirus Production

○ Retrovirus Preparation

O Preparation of the 2lg-B7-H3-GFP Fusion Protein for the $T$ Cell Staining

O Transduction and Expansion of Human T Cells

O Generation of Murine CAR-T Cells

O Immunohistochemistry and Tissue Histopathology

O ELISA

O Flow Cytometry

O Co-culture Experiments

○ Proliferation Assay

O Xenogeneic Mouse Models

○ Generation of Murine Bone Marrow Derived Dendritic Cells (BMDCs)

O Evaluate Toxicity of mB7-H3.CAR-Ts in C57BL/6J Immunocompetent Mice

O Murine PDAC Orthotopic Model in C57BL/6J Mice

O Measurement of the Binding Affinity of the $376.96 \mathrm{mAb}$ to Human and Murine B7-H3

O Stimulation of B7-H3.CAR-Ts with Plate-Bound B7$\mathrm{H} 3-\mathrm{Fc}$ Fusion Proteins

O Measurement of the Copy Numbers of mB7-H3.CAR

- QUANTIFICATION AND STATISTICAL ANALYSIS

\section{SUPPLEMENTAL INFORMATION}

Supplemental Information includes eight figures and four tables and can be found with this article online at https://doi.org/10.1016/j.ccell.2019.01.002.

\section{ACKNOWLEDGMENTS}

This work was supported in part by University Cancer Research Fund at the University of North Carolina at Chapel Hill, United States (G.D.); R01CA193140-03 from National Cancer Institute, United States (G.D.); Rivkin Center for Ovarian Cancer, United States (G.D.); and W81XWH-16-10501 from the Department of Defense, United States (S.F. and G.D.). S.F. is supported by W81XWH-16-1-0500 from the Department of Defense, United States; R01DE028172 from National Institute of Dental \& Craniofacial Reseacrh, United States, and R03CA223886 from National Cancer Institute, United States. Histological services are provided by the Histology Research Core Facility in the Department of Cell Biology and Physiology at the University of North Carolina at Chapel Hill (UNC). Tissue section service and immunohistochemistry were provided by the Histology Research Core Facility in the Department of Cell Biology and Physiology at UNC. Animal histopathology and clinical services were performed by the Animal Histopathology \& Laboratory Medicine Core at UNC, which is supported in part by an National Cancer Institute Center Core support grant (5P30CA016086-41), United States, to the UNC Lineberger Comprehensive Cancer Center (UNC-LCCC). The small animal imaging core and flow cytometry core facilities are supported in part by an National Cancer Institute
Cancer core grant (P30-CA016086-40), United States. The frozen human PDAC specimens were provided by the Tissue Procurement Facility at UNC-LCCC. We thank Charlene Santos and the Animal Studies Core Facility for providing mice and surgery service for the PDAC-PDX mouse model. Finally, we would like to thank Dr. Hongxia Li for her technical support and Dr. Song Zhang for his critical reading of the manuscript, helpful discussion, and suggestions during revision of the manuscript.

\section{AUTHOR CONTRIBUTIONS}

Conceptualization, H.D., K.H., S.A., Y.P.-G., J.J.Y., S.F., B.S., and G.D.; Methodology, H.D., K.H., S.A., N.P.K., S.A.M., K.T., B.M., D.M., S.G.H., Y.X., C.S., Y.C., X.M., Y.P.-G., J.J.Y., R.L., B.S., S.F., and G.D.; Investigation, H.D., K.H., S.A., N.P.K., S.A.M., K.G., Y.P.-G., J.J.Y., B.S., and G.D.; Writing - Original Draft, H.D. and G.D.; Writing - Review \& Editing, all authors; Resources, S.G.H., J.J.Y., Y.P.-G., X.W., C.R.F., and S.F.; Supervision, Y.P.-G., J.J.Y., S.F., B.S., and G.D.

\section{DECLARATION OF INTERESTS}

Drs. Dotti and Savoldo have sponsor research agreements with Bluebird Bio, Cell Medica, and Bellicum Pharmaceutical. Dr. Dotti serves on the scientific advisory board of MolMed S.p.A. Drs. Dotti, Ferrone S., Ferrone C.R., and Du filed a patent for the CAR targeting $\mathrm{B} 7-\mathrm{H} 3$. The other authors declare no competing interests.

Received: October 17, 2017

Revised: October 31, 2018

Accepted: January 2, 2019

Published: February 11, 2019

\section{REFERENCES}

Ahmed, N., Brawley, V., Hegde, M., Bielamowicz, K., Kalra, M., Landi, D., Robertson, C., Gray, T.L., Diouf, O., Wakefield, A., et al. (2017). HER2-specific chimeric antigen receptor-modified virus-specific T cells for progressive glioblastoma: a phase 1 dose-escalation trial. JAMA Oncol. 3, 1094-1101.

Ahmed, N., Brawley, V.S., Hegde, M., Robertson, C., Ghazi, A., Gerken, C., Liu, E., Dakhova, O., Ashoori, A., Corder, A., et al. (2015). Human epiderma growth factor receptor 2 (HER2) -specific chimeric antigen receptor-modified T cells for the immunotherapy of HER2-positive sarcoma. J. Clin. Oncol. 33, 1688-1696.

Balakrishnan, A., Goodpaster, T., Randolph-Habecker, J., Hoffstrom, B.G., Jalikis, F.G., Koch, L.K., Berger, C., Kosasih, P.L., Rajan, A., Sommermeyer, D., et al. (2017). Analysis of ROR1 protein expression in human cancer and normal tissues. Clin. Cancer Res. 23, 3061-3071.

Baskar, S., Kwong, K.Y., Hofer, T., Levy, J.M., Kennedy, M.G., Lee, E., Staudt, L.M., Wilson, W.H., Wiestner, A., and Rader, C. (2008). Unique cell surface expression of receptor tyrosine kinase ROR1 in human B-cell chronic lymphocytic leukemia. Clin. Cancer Res. 14, 396-404.

Bayne, L.J., Beatty, G.L., Jhala, N., Clark, C.E., Rhim, A.D., Stanger, B.Z., and Vonderheide, R.H. (2012). Tumor-derived granulocyte-macrophage colonystimulating factor regulates myeloid inflammation and $\mathrm{T}$ cell immunity in pancreatic cancer. Cancer Cell 21, 822-835.

Beatty, G.L., Haas, A.R., Maus, M.V., Torigian, D.A., Soulen, M.C., Plesa, G., Chew, A., Zhao, Y., Levine, B.L., Albelda, S.M., et al. (2014). Mesothelin-specific chimeric antigen receptor mRNA-engineered $\mathrm{T}$ cells induce anti-tumor activity in solid malignancies. Cancer Immunol. Res. 2, 112-120.

Benzon, B., Zhao, S.G., Haffner, M.C., Takhar, M., Erho, N., Yousefi, K., Hurley, P., Bishop, J.L., Tosoian, J., Ghabili, K., et al. (2017). Correlation of $\mathrm{B} 7-\mathrm{H} 3$ with androgen receptor, immune pathways and poor outcome in prostate cancer: an expression-based analysis. Prostate Cancer Prostatic Dis. 20, 28-35.

Brentjens, R.J., Davila, M.L., Riviere, I., Park, J., Wang, X., Cowell, L.G., Bartido, S., Stefanski, J., Taylor, C., Olszewska, M., et al. (2013). CD19-targeted $\mathrm{T}$ cells rapidly induce molecular remissions in adults with 
chemotherapy-refractory acute lymphoblastic leukemia. Sci. Transl. Med. 5, 177 ra138.

Caruana, I., Savoldo, B., Hoyos, V., Weber, G., Liu, H., Kim, E.S., Ittmann, M.M., Marchetti, D., and Dotti, G. (2015). Heparanase promotes tumor infiltration and antitumor activity of CAR-redirected T lymphocytes. Nat. Med. 21, 524-529.

Chapoval, A.I., Ni, J., Lau, J.S., Wilcox, R.A., Flies, D.B., Liu, D., Dong, H., Sica, G.L., Zhu, G., Tamada, K., et al. (2001). B7-H3: a costimulatory molecule for T cell activation and IFN-gamma production. Nat. Immunol. 2, 269-274.

Chen, X., Quinn, E.M., Ni, H., Wang, J., Blankson, S., Redmond, H.P., Wang, J.H., and Feng, X. (2012). B7-H3 participates in the development of experimental pneumococcal meningitis by augmentation of the inflammatory response via a TLR2-dependent mechanism. J. Immunol. 189, 347-355.

Dave, H., Anver, M.R., Butcher, D.O., Brown, P., Khan, J., Wayne, A.S., Baskar, S., and Rader, C. (2012). Restricted cell surface expression of receptor tyrosine kinase ROR1 in pediatric B-lineage acute lymphoblastic leukemia suggests targetability with therapeutic monoclonal antibodies. PLoS One 7 , e52655.

Di Stasi, A., Tey, S.K., Dotti, G., Fujita, Y., Kennedy-Nasser, A., Martinez, C., Straathof, K., Liu, E., Durett, A.G., Grilley, B., et al. (2011). Inducible apoptosis as a safety switch for adoptive cell therapy. N. Engl. J. Med. 365, 1673-1683.

Diaconu, I., Ballard, B., Zhang, M., Chen, Y., West, J., Dotti, G., and Savoldo, B. (2017). Inducible caspase-9 selectively modulates the toxicities of CD19specific chimeric antigen receptor-modified T cells. Mol. Ther. 25, 580-592.

Dotti, G., Gottschalk, S., Savoldo, B., and Brenner, M.K. (2014). Design and development of therapies using chimeric antigen receptor-expressing T cells. Immunol. Rev. 257, 107-126.

Fauci, J.M., Sabbatino, F., Wang, Y., Londono-Joshi, A.I., Straughn, J.M., Jr., Landen, C.N., Ferrone, S., and Buchsbaum, D.J. (2014). Monoclonal antibodybased immunotherapy of ovarian cancer: targeting ovarian cancer cells with the B7-H3-specific mAb 376.96. Gynecol. Oncol. 132, 203-210.

Hingorani, S.R., Wang, L., Multani, A.S., Combs, C., Deramaudt, T.B., Hruban, R.H., Rustgi, A.K., Chang, S., and Tuveson, D.A. (2005). Trp53R172H and KrasG12D cooperate to promote chromosomal instability and widely metastatic pancreatic ductal adenocarcinoma in mice. Cancer Cell 7, 469-483.

Hofmeyer, K.A., Ray, A., and Zang, X. (2008). The contrasting role of B7-H3. Proc. Natl. Acad. Sci. U S A 105, 10277-10278.

Hoyos, V., Savoldo, B., Quintarelli, C., Mahendravada, A., Zhang, M., Vera, J., Heslop, H.E., Rooney, C.M., Brenner, M.K., and Dotti, G. (2010). Engineering CD19-specific T lymphocytes with interleukin-15 and a suicide gene to enhance their anti-lymphoma/leukemia effects and safety. Leukemia 24, 1160-1170.

Imai, K., Wilson, B.S., Bigotti, A., Natali, P.G., and Ferrone, S. (1982). A 94,000dalton glycoprotein expressed by human melanoma and carcinoma cells. J. Natl. Cancer Inst. 68, 761-769.

Inamura, K., Yokouchi, Y., Kobayashi, M., Sakakibara, R., Ninomiya, H., Subat, S., Nagano, H., Nomura, K., Okumura, S., Shibutani, T., et al. (2017). Tumor B7-H3 (CD276) expression and smoking history in relation to lung adenocarcinoma prognosis. Lung Cancer 103, 44-51.

Kasten, B.B., Arend, R.C., Katre, A.A., Kim, H., Fan, J., Ferrone, S., Zinn, K.R., and Buchsbaum, D.J. (2017). B7-H3-targeted 212Pb radioimmunotherapy of ovarian cancer in preclinical models. Nucl. Med. Biol. 47, 23-30.

Kochenderfer, J.N., Yu, Z., Frasheri, D., Restifo, N.P., and Rosenberg, S.A. (2010). Adoptive transfer of syngeneic T cells transduced with a chimeric antigen receptor that recognizes murine CD19 can eradicate lymphoma and normal B cells. Blood 116, 3875-3886.

Kramer, K., Kushner, B.H., Modak, S., Pandit-Taskar, N., Smith-Jones, P., Zanzonico, P., Humm, J.L., Xu, H., Wolden, S.L., Souweidane, M.M., et al. (2010). Compartmental intrathecal radioimmunotherapy: results for treatment for metastatic CNS neuroblastoma. J. Neurooncol. 97, 409-418.

Lamers, C.H., Klaver, Y., Gratama, J.W., Sleijfer, S., and Debets, R. (2016). Treatment of metastatic renal cell carcinoma (mRCC) with CAIX CAR-engineered T-cells - a completed study overview. Biochem. Soc. Trans. 44, 951-959.
Lamers, C.H., Sleijfer, S., van Steenbergen, S., van Elzakker, P., van Krimpen, B., Groot, C., Vulto, A., den Bakker, M., Oosterwijk, E., Debets, R., et al. (2013). Treatment of metastatic renal cell carcinoma with CAIX CAR-engineered T cells: clinical evaluation and management of on-target toxicity. Mol. Ther. 21, 904-912.

Lee, Y.H., Martin-Orozco, N., Zheng, P., Li, J., Zhang, P., Tan, H., Park, H.J., Jeong, M., Chang, S.H., Kim, B.S., et al. (2017). Inhibition of the B7-H3 immune checkpoint limits tumor growth by enhancing cytotoxic lymphocyte function. Cell Res. 27, 1034-1045.

Leitner, J., Klauser, C., Pickl, W.F., Stockl, J., Majdic, O., Bardet, A.F., Kreil, D.P., Dong, C., Yamazaki, T., Zlabinger, G., et al. (2009). B7-H3 is a potent inhibitor of human T-cell activation: No evidence for B7-H3 and TREML2 interaction. Eur. J. Immunol. 39, 1754-1764.

Loo, D., Alderson, R.F., Chen, F.Z., Huang, L., Zhang, W., Gorlatov, S., Burke, S., Ciccarone, V., Li, H., Yang, Y., et al. (2012). Development of an Fcenhanced anti-B7-H3 monoclonal antibody with potent antitumor activity. Clin. Cancer Res. 18, 3834-3845.

Loos, M., Hedderich, D.M., Friess, H., and Kleeff, J. (2010). B7-H3 and its role in antitumor immunity. Clin. Dev. Immunol. 2010, 683875.

Loos, M., Hedderich, D.M., Ottenhausen, M., Giese, N.A., Laschinger, M., Esposito, I., Kleeff, J., and Friess, H. (2009). Expression of the costimulatory molecule $\mathrm{B} 7-\mathrm{H} 3$ is associated with prolonged survival in human pancreatic cancer. BMC Cancer 9, 463.

Matheu, M.P., Sen, D., Cahalan, M.D., and Parker, I. (2008). Generation of bone marrow derived murine dendritic cells for use in 2-photon imaging. J. Vis. Exp. https://doi.org/10.3791/773.

Maude, S.L., Frey, N., Shaw, P.A., Aplenc, R., Barrett, D.M., Bunin, N.J., Chew, A., Gonzalez, V.E., Zheng, Z., Lacey, S.F., et al. (2014). Chimeric antigen receptor T cells for sustained remissions in leukemia. N. Engl. J. Med. 371, 1507-1517.

Modak, S., Kramer, K., Gultekin, S.H., Guo, H.F., and Cheung, N.K. (2001). Monoclonal antibody $8 \mathrm{H} 9$ targets a novel cell surface antigen expressed by a wide spectrum of human solid tumors. Cancer Res. 61, 4048-4054.

Morgan, R.A., Yang, J.C., Kitano, M., Dudley, M.E., Laurencot, C.M., and Rosenberg, S.A. (2010). Case report of a serious adverse event following the administration of $\mathrm{T}$ cells transduced with a chimeric antigen receptor recognizing ERBB2. Mol. Ther. 18, 843-851.

Newick, K., O'Brien, S., Moon, E., and Albelda, S.M. (2017). CART cell therapy for solid tumors. Annu. Rev. Med. 68, 139-152.

O'Rourke, D.M., Nasrallah, M.P., Desai, A., Melenhorst, J.J., Mansfield, K., Morrissette, J.J.D., Martinez-Lage, M., Brem, S., Maloney, E., Shen, A., et al. (2017). A single dose of peripherally infused EGFRvIll-directed CAR $T$ cells mediates antigen loss and induces adaptive resistance in patients with recurrent glioblastoma. Sci. Transl. Med. 9, https://doi.org/10.1126/scitransImed.aaa0984.

Parker, A.S., Heckman, M.G., Sheinin, Y., Wu, K.J., Hilton, T.W., Diehl, N.N., Pisansky, T.M., Schild, S.E., Kwon, E.D., and Buskirk, S.J. (2011). Evaluation of B7-H3 expression as a biomarker of biochemical recurrence after salvage radiation therapy for recurrent prostate cancer. Int. J. Radiat. Oncol. Biol. Phys. 79, 1343-1349.

Picarda, E., Ohaegbulam, K.C., and Zang, X. (2016). Molecular pathways: targeting B7-H3 (CD276) for human cancer immunotherapy. Clin. Cancer Res. 22, 3425-3431.

Prasad, D.V., Nguyen, T., Li, Z., Yang, Y., Duong, J., Wang, Y., and Dong, C. (2004). Murine B7-H3 is a negative regulator of T cells. J. Immunol. 173, 2500-2506.

Qin, X., Zhang, H., Ye, D., Dai, B., Zhu, Y., and Shi, G. (2013). B7-H3 is a new cancer-specific endothelial marker in clear cell renal cell carcinoma. Onco Targets Ther. 6, 1667-1673.

Roth, T.J., Sheinin, Y., Lohse, C.M., Kuntz, S.M., Frigola, X., Inman, B.A., Krambeck, A.E., McKenney, M.E., Karnes, R.J., Blute, M.L., et al. (2007). B7-H3 ligand expression by prostate cancer: a novel marker of prognosis and potential target for therapy. Cancer Res. 67, 7893-7900. 
Seaman, S., Zhu, Z., Saha, S., Zhang, X.M., Yang, M.Y., Hilton, M.B., Morris, K., Szot, C., Morris, H., Swing, D.A., et al. (2017). Eradication of tumors through simultaneous ablation of CD276/B7-H3-positive tumor cells and tumor vasculature. Cancer Cell 31, 501-515.e8.

Siolas, D., and Hannon, G.J. (2013). Patient-derived tumor xenografts: transforming clinical samples into mouse models. Cancer Res. 73, 5315-5319.

Sohara, Y., Shimada, H., Scadeng, M., Pollack, H., Yamada, S., Ye, W., Reynolds, C.P., and DeClerck, Y.A. (2003). Lytic bone lesions in human neuroblastoma xenograft involve osteoclast recruitment and are inhibited by bisphosphonate. Cancer Res. 63, 3026-3031.

Song, L., Asgharzadeh, S., Salo, J., Engell, K., Wu, H.W., Sposto, R., Ara, T., Silverman, A.M., DeClerck, Y.A., Seeger, R.C., et al. (2009). Valpha24-invariant NKT cells mediate antitumor activity via killing of tumor-associated macrophages. J. Clin. Invest. 119, 1524-1536.

Souweidane, M.M., Kramer, K., Pandit-Taskar, N., Zhou, Z., Haque, S., Zanzonico, P., Carrasquillo, J.A., Lyashchenko, S.K., Thakur, S.B., Donzelli, M., et al. (2018). Convection-enhanced delivery for diffuse intrinsic pontine glioma: a single-centre, dose-escalation, phase 1 trial. Lancet Oncol. 19, 1040-1050.

Steinberger, P., Majdic, O., Derdak, S.V., Pfistershammer, K., Kirchberger, S., Klauser, C., Zlabinger, G., Pickl, W.F., Stockl, J., and Knapp, W. (2004). Molecular characterization of human $4 \mathrm{lg}-\mathrm{B} 7-\mathrm{H} 3$, a member of the B7 family with four Ig-like domains. J. Immunol. 172, 2352-2359.

Suh, W.K., Gajewska, B.U., Okada, H., Gronski, M.A., Bertram, E.M., Dawicki, W., Duncan, G.S., Bukczynski, J., Plyte, S., Elia, A., et al. (2003). The B7 family member B7-H3 preferentially down-regulates T helper type 1-mediated immune responses. Nat. Immunol. 4, 899-906.

Tarek, N., Le Luduec, J.B., Gallagher, M.M., Zheng, J., Venstrom, J.M., Chamberlain, E., Modak, S., Heller, G., Dupont, B., Cheung, N.K., et al. (2012). Unlicensed NK cells target neuroblastoma following anti-GD2 antibody treatment. J. Clin. Invest. 122, 3260-3270.

Tentler, J.J., Tan, A.C., Weekes, C.D., Jimeno, A., Leong, S., Pitts, T.M., Arcaroli, J.J., Messersmith, W.A., and Eckhardt, S.G. (2012). Patient-derived tumour xenografts as models for oncology drug development. Nat. Rev. Clin. Oncol. 9, 338-350.

Ueno, T., Yeung, M.Y., McGrath, M., Yang, S., Zaman, N., Snawder, B., Padera, R.F., Magee, C.N., Gorbatov, R., Hashiguchi, M., et al. (2012). Intact
B7-H3 signaling promotes allograft prolongation through preferential suppression of Th1 effector responses. Eur. J. Immunol. 42, 2343-2353.

Veenstra, R.G., Flynn, R., Kreymborg, K., McDonald-Hyman, C., Saha, A., Taylor, P.A., Osborn, M.J., Panoskaltsis-Mortari, A., Schmitt-Graeff, A., Lieberknect, E., et al. (2015). B7-H3 expression in donor T cells and host cells negatively regulates acute graft-versus-host disease lethality. Blood 125 3335-3346.

Vera, J., Savoldo, B., Vigouroux, S., Biagi, E., Pule, M., Rossig, C., Wu, J., Heslop, H.E., Rooney, C.M., Brenner, M.K., et al. (2006). T lymphocytes redirected against the kappa light chain of human immunoglobulin efficiently kill mature B lymphocyte-derived malignant cells. Blood 108, 3890-3897.

Vigdorovich, V., Ramagopal, U.A., Lazar-Molnar, E., Sylvestre, E., Lee, J.S. Hofmeyer, K.A., Zang, X., Nathenson, S.G., and Almo, S.C. (2013). Structure and $\mathrm{T}$ cell inhibition properties of B7 family member, B7-H3. Structure 21, 707-717.

Walker, A.J., Majzner, R.G., Zhang, L., Wanhainen, K., Long, A.H., Nguyen S.M., Lopomo, P., Vigny, M., Fry, T.J., Orentas, R.J., et al. (2017). Tumor antigen and receptor densities regulate efficacy of a chimeric antigen receptor targeting anaplastic lymphoma kinase. Mol. Ther. 25, 2189-2201.

Xu, Y., Zhang, M., Ramos, C.A., Durett, A., Liu, E., Dakhova, O., Liu, H., Creighton, C.J., Gee, A.P., Heslop, H.E., et al. (2014). Closely related T-memory stem cells correlate with in vivo expansion of CAR.CD19-T cells and are preserved by IL-7 and IL-15. Blood 123, 3750-3759.

Yamato, I., Sho, M., Nomi, T., Akahori, T., Shimada, K., Hotta, K., Kanehiro, H., Konishi, N., Yagita, H., and Nakajima, Y. (2009). Clinical importance of B7-H3 expression in human pancreatic cancer. Br. J. Cancer 101, 1709-1716.

Zang, X., Sullivan, P.S., Soslow, R.A., Waitz, R., Reuter, V.E., Wilton, A., Thaler, H.T., Arul, M., Slovin, S.F., Wei, J., et al. (2010). Tumor associated endothelial expression of $\mathrm{B} 7-\mathrm{H} 3$ predicts survival in ovarian carcinomas. Mod. Pathol. 23, 1104-1112.

Zang, X., Thompson, R.H., Al-Ahmadie, H.A., Serio, A.M., Reuter, V.E., Eastham, J.A., Scardino, P.T., Sharma, P., and Allison, J.P. (2007). B7-H3 and $B 7 x$ are highly expressed in human prostate cancer and associated with disease spread and poor outcome. Proc. Natl. Acad. Sci. U S A 104 , 19458-19463. 


\section{STAR $\star$ METHODS}

\section{KEY RESOURCES TABLE}

\begin{tabular}{|c|c|c|}
\hline REAGENT or RESOURCE & SOURCE & IDENTIFIER \\
\hline \multicolumn{3}{|l|}{ Antibodies } \\
\hline B7-H3-BV421 (clone 7-517) & BD Biosciences & $\begin{array}{l}\text { Cat\# 565829, } \\
\text { RRID:AB_2739369 }\end{array}$ \\
\hline CD3-APC-H7 (clone SK7) & BD Biosciences & $\begin{array}{l}\text { Cat\# 560176, } \\
\text { RRID:AB_1645475 }\end{array}$ \\
\hline CD4-BV421 (clone RPA-T4) & BD Biosciences & $\begin{array}{l}\text { Cat\# 562424, } \\
\text { RRID:AB_11154417 }\end{array}$ \\
\hline CD4-BV510 (clone SK3) & BD Biosciences & $\begin{array}{l}\text { Cat\# 562970, } \\
\text { RRID:AB_2744424 }\end{array}$ \\
\hline CD4-BV711 (clone SK3) & BD Biosciences & $\begin{array}{l}\text { Cat\# 563028, } \\
\text { RRID:AB_2737961 }\end{array}$ \\
\hline CD8-FITC (clone SK1) & BD Biosciences & Cat\# 347313, RRID:AB_400279 \\
\hline CD8-Alexa Fluor 700 (clone RPA-T8) & BD Biosciences & $\begin{array}{l}\text { Cat\# 561453, } \\
\text { RRID:AB_10643765 }\end{array}$ \\
\hline CD8-APC (clone SK1) & BD Biosciences & Cat\# 340584, RRID:AB_400526 \\
\hline CD19-APC (clone HIB19) & BD Biosciences & Cat\# 555415, RRID:AB_398597 \\
\hline CD19-PE (clone SJ25C1) & BD Biosciences & Cat\# 340364, RRID:AB_400018 \\
\hline CD27-BV421 (clone M-T271) & BD Biosciences & $\begin{array}{l}\text { Cat\# 562513, } \\
\text { RRID:AB_11153497 }\end{array}$ \\
\hline CD28-APC (clone CD28.2) & BD Biosciences & Cat\# 559770, RRID:AB_398666 \\
\hline CD28-PE-Cy7 (clone CD28.2) & BD Biosciences & $\begin{array}{l}\text { Cat\# 560684, } \\
\text { RRID:AB_1727459 }\end{array}$ \\
\hline CD45-PE (clone HI30) & BD Biosciences & Cat\# 555483, RRID:AB_395875 \\
\hline CD45RA-BV605 (clone HI100) & BD Biosciences & $\begin{array}{l}\text { Cat\# 562886, } \\
\text { RRID:AB_2737865 }\end{array}$ \\
\hline CD45RA-PE (clone HI100) & BD Biosciences & Cat\# 555489, RRID:AB_395880 \\
\hline CD62L-BV605 (clone DREG-56) & BD Biosciences & $\begin{array}{l}\text { Cat\# 562719, } \\
\text { RRID:AB_2744441 }\end{array}$ \\
\hline CCR7-FITC (clone 150503) & BD Biosciences & $\begin{array}{l}\text { Cat\# 561271, } \\
\text { RRID:AB_10561679 }\end{array}$ \\
\hline PD-1-PE-Cy7 (clone EH12.1) & BD Biosciences & $\begin{array}{l}\text { Cat\# 561272, } \\
\text { RRID:AB_10611585 }\end{array}$ \\
\hline PD-L1-PE (clone MIH1) & BD Biosciences & Cat\# 557924, RRID:AB_647198 \\
\hline TIM3-BV711 (clone 7D3) & BD Biosciences & $\begin{array}{l}\text { Cat\# 565566, } \\
\text { RRID:AB_2744370 }\end{array}$ \\
\hline mCD3e-APC-Cy7 (clone 145-2C11) & BD Biosciences & Cat\# 557596, RRID:AB_396759 \\
\hline mCD4-PerCP-Cy5.5 (clone RM4-5) & BD Biosciences & Cat\# 550954, RRID:AB_393977 \\
\hline mCD8a-BV510 (clone 53-6.7) & BD Biosciences & $\begin{array}{l}\text { Cat\# 563068, } \\
\text { RRID:AB_2687548 }\end{array}$ \\
\hline mCD11b-APC (clone M1/70) & BD Biosciences & Cat\# 553312, RRID:AB_398535 \\
\hline mCD11c-BV421 (clone HL3) & BD Biosciences & $\begin{array}{l}\text { Cat\# 562782, } \\
\text { RRID:AB_2737789 }\end{array}$ \\
\hline mCD19-FITC (clone 1D3) & BD Biosciences & Cat\# 553785, RRID:AB_395049 \\
\hline mLy-6G-PE (clone 1A8) & BD Biosciences & $\begin{array}{l}\text { Cat\# 561104, } \\
\text { RRID:AB_10563079 }\end{array}$ \\
\hline mNK-1.1-PE-Cy7 (clone PK136) & Biolegend & Cat\# 108714, RRID:AB_389364 \\
\hline mPD-1-PE (clone J43) & BD Biosciences & Cat\# 551892, RRID:AB_394284 \\
\hline Goat anti-mouse Ig-APC (Polyclonal) & BD Biosciences & Cat\# 550826, RRID:AB_398465 \\
\hline & & (Continued on next pa \\
\hline
\end{tabular}




\begin{tabular}{|c|c|c|}
\hline \multicolumn{3}{|l|}{ Continued } \\
\hline REAGENT or RESOURCE & SOURCE & IDENTIFIER \\
\hline Goat Anti-Mouse IgG-AF647 (Anti-Fab) (Polyclonal) & Jackson ImmunoResearch Labs & $\begin{array}{l}\text { Cat\# 115-606-072, } \\
\text { RRID:AB_2338928 }\end{array}$ \\
\hline Anti-B7-H3 (clone EPNCIR122) & Abcam & $\begin{array}{l}\text { Cat\# ab134161, } \\
\text { RRID:AB_2687929 }\end{array}$ \\
\hline Anti-B7-H3 (clone 376.96) & $\begin{array}{l}\text { Generated by Dr. Soldano Ferrone } \\
\text { (Imai et al., 1982) }\end{array}$ & N/A \\
\hline Anti-m/hCD3 (clone SP7) (for IHC) & Novus Biologicals & $\begin{array}{l}\text { Cat\# NB600-1441, } \\
\text { RRID:AB_789102 }\end{array}$ \\
\hline Anti-CD3 (clone OKT3) & Miltenyi Biotec & $\begin{array}{l}\text { Cat\# 130-093-387, } \\
\text { RRID:AB_1036144 }\end{array}$ \\
\hline Anti-CD28 (clone CD28.2) & BD Biosciences & Cat\# 555725, RRID:AB_396068 \\
\hline Anti-CD19.CAR (clone 233-4A) & $\begin{array}{l}\text { Generated by the Core Facility at MD Anderson } \\
\text { Cancer Center }\end{array}$ & N/A \\
\hline $\begin{array}{l}\text { HRP polymer conjugated goat anti-mouse } \\
\text { Ig secondary Ab }\end{array}$ & Dako & Cat\# K4000 \\
\hline $\begin{array}{l}\text { HRP polymer conjugated goat anti-rabbit } \\
\text { Ig secondary Ab }\end{array}$ & Dako & Cat\# K4002 \\
\hline \multicolumn{3}{|l|}{ Biological Samples } \\
\hline Human normal tissue array & US Biomax & FDA903a \\
\hline Mouse normal tissue array & BioChain & T6334701-2 \\
\hline Human ovarian cancer tissue array & US Biomax & FOV401 \\
\hline Human PDAC tissues & $\begin{array}{l}\text { University of North Carolina at Chapel Hill } \\
\text { tissue bank https://unclineberger.org/research/ } \\
\text { core-facilities/tissue-procurement }\end{array}$ & $\mathrm{N} / \mathrm{A}$ \\
\hline \multicolumn{3}{|l|}{ Chemicals, Peptides, and Recombinant Proteins } \\
\hline $2 \lg -\mathrm{B} 7-\mathrm{H} 3-\mathrm{Fc}$ & ACRO Biosystems & CAT\# B73-H5253-100ug \\
\hline 2lg-B7-H3-His & ACRO Biosystems & CAT\# B73-H52E2-100ug \\
\hline 4lg-B7-H3-Fc & AdipoGen LifeSciences & CAT\# CHI-HF-211B7H3B-C100 \\
\hline $4 \mathrm{lg}-\mathrm{B} 7-\mathrm{H} 3-\mathrm{His}$ & Novus Biologicals & CAT\# NBP2-59914-250ug \\
\hline mB7-H3-Fc & ACRO Biosystems & CAT\# B73-M5255-100ug \\
\hline $\mathrm{mB} 7-\mathrm{H} 3-\mathrm{His}$ & ACRO Biosystems & CAT\# B73-M52H4-100ug \\
\hline 2lg-B7-H3-GFP & This paper & $\mathrm{N} / \mathrm{A}$ \\
\hline Murine GM-CSF & PeproTech & CAT\# 315-03 \\
\hline Human IL-7 & PeproTech & CAT\# 200-07 \\
\hline Human IL-15 & PeproTech & CAT\# 200-15 \\
\hline Normal goat serum & Sigma-Aldrich & CAT\# G9023-10ML \\
\hline RetroNectin & Takara & CAT\# T100B \\
\hline GeneJuice & Merck Millipore & CAT\# 70967 \\
\hline Phusion PCR master mix & Thermo & CAT\# F-531 \\
\hline Xylenes & Fisher Chemical & CAT\# X3P-1GAL \\
\hline $10 \%$ neutral buffered formalin & Fisher Chemical & CAT\# SF100-4 \\
\hline XenoLight D-Luciferin & Perkin Elmer & CAT\# 122799 \\
\hline 4\% Paraformaldehyde Solution in PBS & Fisher Chemical & CAT\# AAJ19943K2 \\
\hline $30 \% \mathrm{H} 2 \mathrm{O} 2$ & Sigma-Aldrich & CAT\# 216763-100ML \\
\hline \multicolumn{3}{|l|}{ Critical Commercial Assays kit } \\
\hline Human IFN-gamma ELISA kit & $R \& D$ systems & CAT\# DY285B \\
\hline Human IL-2 ELISA kit & R\&D systems & CAT\# DY202 \\
\hline Murine IFN-gamma ELISA kit & R\&D systems & CAT\# DY485-05 \\
\hline Murine IL-2 ELISA kit & R\&D systems & CAT\# DY402-05 \\
\hline
\end{tabular}




\begin{tabular}{|c|c|c|}
\hline Continued & & \\
\hline REAGENT or RESOURCE & SOURCE & IDENTIFIER \\
\hline ELISA substrate reagent pack & R\&D systems & CAT\# DY999 \\
\hline DAB substrate kit & Cell Signaling technology & CAT\# $8059 \mathrm{~S}$ \\
\hline \multicolumn{3}{|l|}{ Experimental Models: Cell Lines } \\
\hline Panc-1 & ATCC & CAT\# CRL-1469 \\
\hline Panc-10.05 & ATCC & CAT\# CRL-2547 \\
\hline Capan-1 & ATCC & CAT\# HTB-79 \\
\hline $\mathrm{BxPC}-3$ & ATCC & CAT\# CRL-1687 \\
\hline AsPC-1 & ATCC & CAT\# CRL-1682 \\
\hline CHLA-255 & $\begin{array}{l}\text { Gift from Dr. Metelitsa, Baylor College of } \\
\text { Medicine, Houston TX }\end{array}$ & N/A \\
\hline LAN-1 & $\begin{array}{l}\text { Gift from Dr. Brenner, Baylor College of } \\
\text { Medicine, Houston TX }\end{array}$ & N/A \\
\hline IMR-32 & ATCC & CAT\# CCL-127 \\
\hline SKNLP & $\begin{array}{l}\text { Gift from Dr. Brenner, Baylor College of } \\
\text { Medicine, Houston TX }\end{array}$ & $\mathrm{N} / \mathrm{A}$ \\
\hline KPC-4662 & $\begin{array}{l}\text { Isolated by Dr. Vonderheide's lab (Bayne } \\
\text { et al., 2012; Hingorani et al., 2005) }\end{array}$ & $\mathrm{N} / \mathrm{A}$ \\
\hline SW626 & ATCC & CAT\# HTB-78 \\
\hline SK-OV-3 & ATCC & CAT\# HTB-77 \\
\hline CaoV-3 & ATCC & CAT\# HTB-75 \\
\hline Raji & ATCC & CAT\# CCL-86 \\
\hline PDAC-2 & $\begin{array}{l}\text { Isolated by Dr. Cristina Ferrone, Massachusetts } \\
\text { General Hospital, Boston, MA }\end{array}$ & $\mathrm{N} / \mathrm{A}$ \\
\hline PDAC-3 & $\begin{array}{l}\text { Isolated by Dr. Cristina Ferrone, Massachusetts } \\
\text { General Hospital, Boston, MA }\end{array}$ & N/A \\
\hline PDAC-6 & $\begin{array}{l}\text { Isolated by Dr. Cristina Ferrone, Massachusetts } \\
\text { General Hospital, Boston, MA }\end{array}$ & $\mathrm{N} / \mathrm{A}$ \\
\hline Panc-1-Ffluc-GFP & This paper & \\
\hline BxPC-3-Ffluc-GFP & This paper & \\
\hline SK-OV-3-Ffluc-GFP & This paper & \\
\hline CHLA-255-Ffluc & $\begin{array}{l}\text { Gift from Dr. Metelitsa, Baylor College of } \\
\text { Medicine, Houston TX }\end{array}$ & \\
\hline KPC-4662-mB7-H3-tg & This paper & \\
\hline \multicolumn{3}{|l|}{ Recombinant DNA } \\
\hline SFG.2lg-B7-H3 & This paper & $\mathrm{N} / \mathrm{A}$ \\
\hline SFG.4lg-B7-H3 & This paper & $\mathrm{N} / \mathrm{A}$ \\
\hline SFG.mB7-H3 & This paper & $\mathrm{N} / \mathrm{A}$ \\
\hline SFG.2lg-B7-H3-GFP & This paper & N/A \\
\hline mB7-H3 cDNA clone & InVivogene & Cat\# puno1-mb7h3 \\
\hline SFG.B7-H3.CAR-28ל & This paper & N/A \\
\hline SFG.B7-H3.CAR-4-1BBל & This paper & $\mathrm{N} / \mathrm{A}$ \\
\hline SFG.mCD19.CAR & This paper & N/A \\
\hline SFG.mB7-H3.CAR & This paper & $\mathrm{N} / \mathrm{A}$ \\
\hline \multicolumn{3}{|l|}{ Software and Algorithms } \\
\hline Flowjo v10. & Flowjo & $\mathrm{N} / \mathrm{A}$ \\
\hline GraphPad Prism & GraphPad Software Inc. & $\mathrm{N} / \mathrm{A}$ \\
\hline Living Image v4.5.2 (IVIS imaging) & Perkin Elmer & $\mathrm{N} / \mathrm{A}$ \\
\hline Aperio color deconvolution v9 & Leica Biosystems & N/A \\
\hline \multicolumn{3}{|l|}{ Other } \\
\hline Counting beads & Invitrogen & Cat\# C36950 \\
\hline Zombie Aqua Fixable Viability Kit & BioLegend & Cat\# 423102 \\
\hline
\end{tabular}




\section{CONTACT FOR REAGENT AND RESOURCE SHARING}

Further information and requests for resources and reagents should be directed to and will be fulfilled by the Lead Contact, Gianpietro Dotti, Email: gdotti@med.unc.edu.

\section{EXPERIMENTAL MODEL AND SUBJECT DETAILS}

\section{Cell Lines and Cell Culture}

Human pancreatic (PDAC) tumor cell lines Panc-1 (Source: male), BxPC-3 (Source: female), Panc-10.05 (Source: male), Capan-1 (Source: male) and AsPC-1 (Source: female), human ovarian cancer (OC) cell lines SW626 (Source: female), SK-OV-3 (Source: female) and CaoV-3 (Source: female), and human neuroblastoma (NB) cell line IMR-32 (Source: male) were purchased from American Type Culture Collection (ATCC). Human NB cell lines CHLA-255 (Source: unknown, initially derived from a metastatic lesion in the brain in a patient with recurrent disease at Children's Hospital Los Angeles (Sohara et al., 2003)) and FFluc-CHLA-255 are gifts from Dr. Metelitsa at Baylor College of Medicine (Houston TX) (Song et al., 2009), and LAN-1 (Source: male) and SKNLP (Source: unknown, initially derived from a patient with NB treated at Memorial Sloan-Kettering Cancer Center (Tarek et al., 2012)) are gifts from Dr. Brenner at Baylor College of Medicine (Houston TX) (Tarek et al., 2012). Human PDAC cell lines PDAC2 (Source: male), PDAC3 (Source: female), and PDAC6 (Source: male) were established at Dana-Farber Cancer Institute and Massachusetts General Hospital by Dr Cristina Ferrone from ascites of PDAC patients. Murine pancreatic tumor cell line KPC-4662 was a gift from Dr. Yuliya Pylayeva-Gupta, originally obtained from Dr. Vonderheide (University of Pennsylvania) (Bayne et al., 2012; Hingorani et al., 2005). The tumor cell line SK-OV-3 was selected three times in vivo in NSG mice to obtain a very aggressive clone. Capan-1 cell lines were cultured in IMDM (Gibco, Invitrogen) supplemented with 10\% FBS (Sigma), 2 mM GlutaMax (Gibco). BxPC-3, Panc-10.05, PDAC-2, PDAC-3, PDAC-6, KPC-4662, SW626, CHLA-255, IMR-32, LAN-1 and SKNLP were cultured in RPMI1640 (Gibco) supplemented with 10\% FBS and 2 mM GlutaMax. AsPC-1 was cultured in RPMl1640 (Gibco) supplemented with $10 \%$ FBS, 2 mM GlutaMax and 1mM Sodium pyruvate (Gibco). Panc-1 and Caov-3 cells were cultured in DMEM (GIBCO) supplemented with 10\% FBS and 2 mM GlutaMax. SK-OV-3 was cultured in McCoy's medium supplemented with 10\% FBS and 2 mM GlutaMax. Penicillin (100 unit/mL) (Gibco) and streptomycin $(100 \mu \mathrm{g} / \mathrm{mL})$ (Gibco) were added to cell culture media. Cells were maintained in a humidified atmosphere containing $5 \% \mathrm{CO}_{2}$ at $37^{\circ} \mathrm{C}$. Panc-1, Panc-10.05, BxPC-3, Capan-1, AsPC-1, PDAC-2, PDAC-3 and PDAC-6 cells were transduced with a retroviral vector encoding GFP. The human B-cell lymphoma Raji (Source: male) cell line obtained from ATCC was transduced with retroviral vectors encoding either human or murine $\mathrm{B} 7-\mathrm{H} 3$, and sorted to generate single cell clones. The murine pancreatic tumor cell line KPC-4662 was transduced with a retroviral vector encoding the murine B7-H3. Panc-1, BxPC-3 and SK-OV-3 cells were also transduced with a retroviral vector encoding the GFP-Firefly-Luciferase (GFP-FFluc) gene (Vera et al., 2006). All cell lines were mycoplasma free, and validated by flow cytometry for surface markers and functional readouts as needed.

\section{Human and Mouse Tissue Samples}

Frozen normal human tissue microarrays (TMA) and human ovarian cancer TMA were purchased from US Biomax (Rockville, USA). Frozen normal mouse TMA were purchased from BioChain Institute Inc. (Newark, USA). The use of this material does not require Institutional Review Board (IRB) approval. Frozen PDAC specimens were obtained from the Tissue Procurement Facility at the Lineberger Comprehensive Cancer Center at the University of North Carolina at Chapel Hill (UNC), and the specimens were collected under an Institutional Review Board (IRB) approved protocol (IRB 90-0573) with obtained informed consent. These deidentified samples are distributed by the facility under non-human subject study IRB approval. For the PDAC-PDX, fresh tumor samples from deidentified PDAC patients were obtained under protocols approved by IRB at UNC with obtained informed consent. All patient-derived tissues were stained with hematoxylin and eosin to confirm histology. Tumors were implanted orthotopically into the pancreas of 6 - 8 weeks old female NSG mice under protocols approved by the Institutional Animal Care and Use Committee at UNC.

\section{In Vivo Mouse Studies}

Male and female 4 - 6 weeks old NSG mice were purchased from the Animal Core Facility at UNC. Male and female 4 - 6 weeks old C57BL/6J mice were purchased from The Jackson Laboratory. All the mice were housed in the Animal Core Facility at UNC. All mouse experiments were performed in accordance with UNC Animal Husbandry and Institutional Animal Care and Use Committee (IACUC) guidelines and were approved by UNC IACUC.

\section{METHOD DETAILS}

\section{Plasmid Construction and Retrovirus Production}

The full-length human 2lg-B7-H3 (GenBank: NM_001329628) and 4lg-B7-H3 (GenBank: NM_001024736) genes were amplified by PCR from cDNA obtained from the Panc-1 cell line, and cloned into the retroviral vector SFG. Murine B7-H3 (GenBank: NM_133983) was amplified by PCR from a plasmid obtained from InVivogene (San Diego, CA), and cloned into the retroviral vector SFG. The 2lgB7-H3-GFP fusion protein was generated by fusing the coding region of 2lg-B7-H3 extracellular domain (1-248 amino acids) with the GFP gene by fusion PCR, and cloned into the retroviral vector SFG. The variable regions of the heavy and light chains of the 376.96 
$\mathrm{mAb}$ were cloned from the 376.96 mouse hybridoma and then cloned as a scFv fragment into previously validated CAR formats that include the human CD8 $\alpha$ hinge and transmembrane domain, CD28 or 4-1BB intracellular costimulatory domains and CD3 $\zeta$ intracellular signaling domain. The B7-H3.CAR cassettes were cloned into the retroviral vector SFG. For the murine version of the B7H3.CAR (mB7-H3.CAR), human CD8 $\alpha, \mathrm{CD} 28$ and $\mathrm{CD} 3 \zeta$ were replaced by murine CD28 and CD3\%. The scFv specific for murine CD19 was previously reported (Kochenderfer et al., 2010).

\section{Retrovirus Preparation}

Retroviral supernatants used for the transduction of human T cells were prepared as previously described (Vera et al., 2006). Briefly, $2 \times 10^{6} 293$ T cells were seeded in $10 \mathrm{~cm}$ cell culture dish and transfected with the plasmid mixture of the retroviral vector, the PegPam-e plasmid encoding MoMLV gag-pol, and the RDF plasmid encoding the RD114 envelope, using the GeneJuice transfection reagent (Merck Millipore), according to the manufacturer's instruction. Similarly, retroviral supernatant used for the transduction of murine T cells was generated by cotransfecting $293 \mathrm{~T}$ cells with the retroviral vector and the pCL-Eco plasmid that encodes gag/pol/env using the GeneJuice transfection reagent. Supernatant containing the retrovirus was collected 48 and 72 hours after transfection, and filtered with $0.45 \mu \mathrm{m}$ filters.

\section{Preparation of the 2lg-B7-H3-GFP Fusion Protein for the T Cell Staining}

The retroviral supernatant encoding 2lg-B7-H3-GFP was generated using the above described retrovirus supernatant preparation procedure. The viral supernatant was used to stably transduce 293T cells. The 2lg-B7-H3-GFP expressing 293T cells were seeded in $10 \mathrm{~cm}$ cell culture dishes $\left(5 \times 10^{6} \mathrm{cells} / \mathrm{dish}\right)$ and the supernatant containing the $2 \mathrm{lg}-\mathrm{B} 7-\mathrm{H} 3-\mathrm{GFP}$ fusion protein was collected at 48 hours, filtered with $0.22 \mu \mathrm{m}$ filter and used for the staining of the B7-H3.CAR-Ts (300 $\mu \mathrm{L} / \mathrm{sample})$ to detect CAR expression.

\section{Transduction and Expansion of Human T Cells}

Buffy coats from healthy donors were purchased from the Gulf Coast Regional Blood Center, Houston, TX. Peripheral blood mononuclear cells (PBMCs) isolated with Lymphoprep density separation (Fresenius Kabi Norge) were activated on plates coated with $1 \mu \mathrm{g} / \mathrm{mL}$ CD3 (Miltenyi Biotec) and $1 \mu \mathrm{g} / \mathrm{mL}$ CD28 (BD Biosciences) agonistic mAbs. On day 2, T lymphocytes were transduced with retroviral supernatants using retronectin-coated plates (Takara Bio Inc., Shiga, Japan). Briefly, non-tissue culture treated 24-well plates are coated overnight with $7 \mu \mathrm{g} / \mathrm{mL}$ retronectin in the cold room, washed once with $1 \mathrm{~mL}$ medium, coated with $1 \mathrm{~mL}$ of the retroviral supernatant per well and centrifuged at $2000 \mathrm{~g}$ for $90 \mathrm{~min}$. After removal of the supernatant, $5 \times 10^{5}$ activated $\mathrm{T}$ cells are plated, and centrifuged at $1000 \mathrm{~g}$ for $10 \mathrm{~min}$. Three days later, T cells are collected and expanded in complete medium (45\% RPMI-1640 and 45\% Click's medium (Irvine Scientific), 10\% FBS (Hyclone), 2 mM GlutaMAX, 100 unit/mL of Penicillin and $100 \mu \mathrm{g} / \mathrm{mL}$ of streptomycin) with IL-7 (10 ng/mL; PeproTech) and IL-15 (5 ng/mL; PeproTech), changing medium every 2 - 3 days (Xu et al., 2014). On day 12 - 14, cells are collected for in vitro and in vivo experiments. T cells were cultured in IL-7/IL-15 depleted medium for two days prior to being used in in vitro functional assays.

\section{Generation of Murine CAR-T Cells}

Murine $\mathrm{CD}^{+}$and $\mathrm{CD} 8^{+} \mathrm{T}$ cells were selected by CD4 and CD8 magnetic Microbeads (Miltenyi Biotec) from splenocytes obtained from C57BL/6J mice and stimulated on plates coated with $1 \mu \mathrm{g} / \mathrm{mL} \mathrm{mCD} 3$ (eBioscience) and $1 \mu \mathrm{g} / \mathrm{mL} \mathrm{mCD} 28 \mathrm{mAbs}$ (eBioscience) for 24 hours. Activated murine T lymphocytes were transduced with retroviral supernatants using retronectin-coated plates (Takara Bio Inc., Shiga, Japan) with the same protocol used to transduce human T cells. After removal from the retronectin plates, $T$ cells were expanded in complete medium (RPMI-1640 (Gibco), 10\% FBS (Hyclone), 2mM GlutaMAX, $100 \mu \mathrm{M} \beta$-mercaptoethanol, 100 unit/mL of Penicillin and $100 \mu \mathrm{g} / \mathrm{mL}$ of streptomycin) with IL-7 (10 ng/mL) and IL-15 (5 ng/mL) changing medium every 2 days. On day 6 - 7 , T cells were collected and used for functional assays in vitro and in vivo.

\section{Immunohistochemistry and Tissue Histopathology}

Frozen PDAC specimens were sectioned by the Histology Research Core Facility at UNC. Slides were dried for 30 minutes at room temperature, and fixed in 4\% PFA in PBS for 15 min, blocked with $3 \% \mathrm{H}_{2} \mathrm{O}_{2}$ (Sigma) in distilled water for 20 minutes, then blocked with $1 \%$ BSA and 10\% normal goat serum (Sigma) in PBS for 1 hour at room temperature. Slides were stained with the primary Ab at $4{ }^{\circ} \mathrm{C}$ overnight. Normal human TMA and tumor tissues were stained with the B7-H3 mAb (clone 376.96, 1:1000 dilution, final concentration $1 \mu \mathrm{g} / \mathrm{mL}$.)(Imai et al., 1982). Murine normal TMA and tumor tissues were stained with the B7-H3 EPNCIR122 mAb (Abcam, Cambridge, USA; 1:500 dilution, final concentration $1.4 \mu \mathrm{g} / \mathrm{mL}$.) that recognizes both human and murine B7-H3 (Seaman et al., 2017). HRP polymer conjugated goat anti-mouse secondary Ab (Dako, code $\mathrm{K} 4000,1: 8$ dilution at $25^{\circ} \mathrm{C}$ for 1.5 hours) was used for human TMA and tumor tissues, while the goat anti-rabbit secondary Ab (Dako, code K4002, 1:8 dilution at $25^{\circ} \mathrm{C}$ for 1.5 hours) was used for murine TMA and tumor tissues. Slides were developed using DAB chromogen (Cell signaling), counterstained with CAT hematoxylin (Biocare medical), dehydrated in ethanol, and cleared in xylene (Fisher chemical). Cover slips were added using histological mounting medium (Fisher, toluene solution). Stained TMA slides were digitally imaged at $20 \times$ objective using the Aperio ScanScope XT (Leica). TMA slides were de-arrayed to visualize individual cores and each core was visually inspected. Folded tissues were excluded from the analysis using a negative pen, and all other artifacts were automatically excluded with the Aperio Genie software. The $\mathrm{B} 7-\mathrm{H} 3$ positive score was measured using Aperio membrane v9 (cell quantification) algorithm. Percentage of positive cells obtained with this algorithm at each intensity level (negative, low, medium, high) were used to calculate the $\mathrm{H}$-Score using the 
formula: $\mathrm{H}-\mathrm{Score}=(\%$ at $1+) * 1+(\%$ at $2+) * 2+(\%$ at $3+) * 3$. The Aperio color deconvolution v9 algorithm with the Genie classifier was also applied to calculate the area and intensity of the positive stain and generate a Score (0-300). For the CD3 staining, formalin fixed and paraffin embedded tumor tissues were cut into $5 \mu \mathrm{m}$ sections by the Histology Research Core Facility at UNC. The sections were deparaffinized and placed in the antigen retrieval buffer (Thermo Scientific, TA-135-HBL). Heat-induced epitope retrieval was performed using a decloaking chamber for 30 seconds at $120^{\circ} \mathrm{C}$ followed by 10 seconds at $90^{\circ} \mathrm{C}$, then blocking with $3 \% \mathrm{H}_{2} \mathrm{O}_{2}$ in distilled water for 20 minutes and 10\% normal goat serum in TBS for 1 hour at room temperature. Slides were incubated with the $\mathrm{CD} 3 \mathrm{Ab}$ (1:250 dilution; Novus Bio, NB600-1441) overnight at $4^{\circ} \mathrm{C}$ and biotinylated goat anti-rabbit IgG secondary Ab (1:500 dilution, Jackson ImmunoResearch, 111-065-144) for 1 hour at room temperature. Staining was visualized using a Vectastain ABC Elite Kit (1:50 dilution, Vector Labs, PK-6100) followed by diaminobenzidine (DAB, Cell signaling). Stained slides were digitally scanned at $20 \times$ magnification using the Aperio ScanScope-XT (Aperio Technologies, Vista, CA), and the digital images were analyzed using Tissue Studio software (Tissue Studio version 2.7 with Tissue Studio Library version 4.4.2; Definiens Inc., Munich, Germany). Specifically, Tissue Studio's Nuclei and Cell Simulation Algorithm was used to detect and enumerate cells that were positive and negative for murine CD3 signal. Positive cell density = the number of positive cells per $\mathrm{mm}^{2}$ area analyzed. Tissue sections and hematoxylin and eosin staining for animal tissue histopathology was performed by the Animal Histopathology \& Laboratory Medicine Core at UNC, and scored by a mouse pathologist.

\section{ELISA}

T cells $\left(1 \times 10^{5}\right.$ or $\left.5 \times 10^{5}\right)$ were co-cultured with tumor cells $\left(5 \times 10^{5}\right)$ in 24 -well plates without the addition of exogenous cytokines. After 24 hours, supernatant was collected and cytokines (IFN $\gamma$ and IL-2) were measured in duplicate using specific ELISA kits (R\&D system) following manufacturer's instructions.

\section{Flow Cytometry}

We performed flow cytometry using Abs specific to human CD3, CD4, CD8, CD19, CD27, CD28, CD45, CD45RA, CD62L, CCR7, B7-H3, PD-1, PD-L1 and TIM3, and murine CD3, CD4, CD8, CD11b, CD11c, CD19, PD-1, Ly-6G and NK1.1 (from BD bioscience and Biolegend) conjugated with BV421, BV510, BV605, BV711, FITC, AF488, PerCP-cy5.5, PE, PE-cy7, APC and APC-cy7 fluorochromes. Expression of human B7-H3 in tumor cell lines was assessed with the $376.96 \mathrm{mAb}$ and confirmed with another B7-H3 Ab clone 7-517 (BD bioscience) (Imai et al., 1982). Expression of murine B7-H3 in BMDCs was assessed with the 376.96 Ab and the B7-H3 Ab clone EPNCIR122 (Abcam) (Seaman et al., 2017). Expression of the B7-H3.CARs was detected using the fusion protein 2lg-B7-H3-GFP or the Fab Ab (Jackson ImmunoResearch Laboratories INC.). Samples were acquired with BD FACSCanto II or BD FACSFortessa using the BD Diva software (BD Biosciences). For each sample a minimum of 10,000 events were acquired and data were analyzed using Flowjo 10.

\section{Co-culture Experiments}

Tumor cells were seeded in 24-well plates at a concentration of $5 \times 10^{5}$ cells/well. T cells were added to the culture at different ratios (E:T of $1: 1 ; 1: 5$, or $1: 10$ ) without the addition of exogenous cytokines. Cells were analyzed at day $5-7$ to measure residual tumor cells and T cells by FACS. Dead cells were gated out by Zombie Aqua Dye (Biolegend) staining while T cells were identified by the expression of CD3 and tumor cells by the expression of GFP (PDAC, OC and NB cell lines), or CD19 (Raji, Raji-2lgB7-H3, Raji-4lgB7-H3 and Raji-mB7H3) or mB7-H3 (KPC-4662-mB7-H3) (Hoyos et al., 2010; Vera et al., 2006).

\section{Proliferation Assay}

T cells were labeled with $1.5 \mathrm{mM}$ carboxyfluorescein diacetate succinimidyl ester (CFSE; Invitrogen) and plated with tumor cells at an E:T ratio of 1:1. CFSE dilution was measured on gated T cells on day 5 using flow cytometry (Hoyos et al., 2010).

\section{Xenogeneic Mouse Models}

For the PDAC orthotopic model, FFluc-Panc- $1\left(2 \times 10^{5}\right)$ or FFluc-BxPC-3 $\left(1 \times 10^{5}\right)$ tumor cells were suspended in $25 \mu \mathrm{L}$ DPBS, mixed with $25 \mu \mathrm{L}$ Matrigel (Corning) and surgically implanted into the pancreas of 8 - 10 weeks old male mice using 28-gauge needle. Briefly, an incision was performed in the left flank and PDAC tumor cells were injected using a 28-gauge needle into the tail of the pancreas. The wound was closed in two layers, with running 4-0 Vicryl, and polypropylene sutures for the skin. Twelve or 28 days after tumor cell

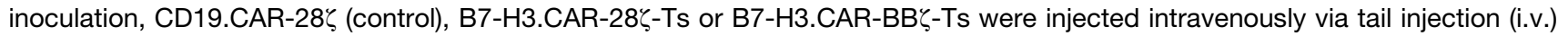
$\left(1 \times 10^{7}\right.$ cells/mouse). For the PDAC metastatic model, 8 - 10 weeks old male or female mice were injected i.v. with FFluc-

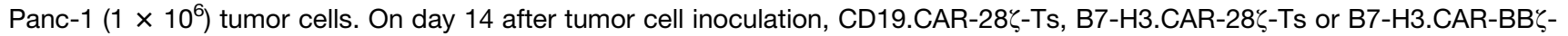
Ts were injected i.v. $\left(1 \times 10^{7}\right.$ cells/mouse). For the Panc- 1 re-challenge model, 6 weeks old female mice were injected i.v. with FFluc-Panc-1 $\left(1 \times 10^{6}\right)$ tumor cells. On day 14 after tumor cell inoculation, CD19.CAR-28 $\zeta-T s, B 7-H 3 . C A R-28 \zeta-T s$ or B7H3.CAR-BB $\zeta$-Ts were injected i.v. $\left(1 \times 10^{7}\right.$ cells/mouse). Twenty-eight days after CAR-Ts treatment, mice were re-challenged with $1 \times 10^{6}$ FFluc-Panc-1 tumor cells and followed for three weeks. Mice received another tumor re-challenged with $1 \times 10^{6}$ FFluc-Panc-1 tumor cells on day 49 and 63 after CAR-Ts treatment. For the PDAC-PDX pancreatic orthotopic xenograft model, human PDAC tumor fragments were orthotopically implanted into the pancreas of female NSG mice. Twenty-one days after

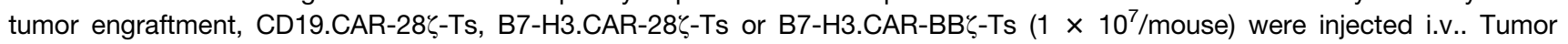
size was monitored by ultrasound (US) imaging on day $-4,15$ and 31 after T cell infusion. Tumor volume was calculated by the 
formula: volume $=0.52 \times$ length $\times$ width $^{2}$. For the NB metastatic model, $6-8$ weeks old male or female NSG mice were injected i.v. with the tumor cell line FFluc-CHLA-255 $\left(2 \times 10^{6}\right.$ cells/mouse). Fourteen days after tumor inoculation, CD19.CAR-28 $\zeta-T s$ $\left(5 \times 10^{6}\right.$ cells/mouse $)$ or B7-H3.CAR-28 - -Ts $\left(2 \times 10^{6}\right.$ or $5 \times 10^{6}$ cells/mouse $)$ were injected i.v.. For the OC xenograft model, the human OC cell line FFluc-SK-OV-3 $\left(5 \times 10^{5}\right.$ cells/mouse) suspended in matrigel was inoculated intraperitoneally (i.p.) into 6 - 8 weeks

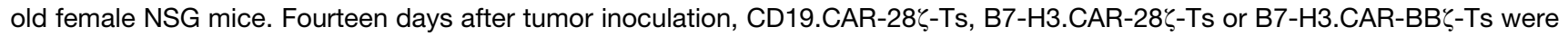
injected either i.p or i.v. $\left(5 \times 10^{6}\right.$ cells/mouse). No randomization was used. Investigators were not blinded, but mice were matched based on the tumor bioluminescence or tumor volume measured by US imaging before assignment to control or treatment groups. Tumor growth was monitored by bioluminescence imaging using IVIS lumina II in vivo imaging system (PerkinElmer) or by US imaging in the PDAC-PDX model. Mice were euthanized when signs of discomfort were detected by the investigators or as recommended by the veterinarian who monitored the mice three times a week, or when luciferase signal reached $1 \times 10^{11}$ photons per second per $\mathrm{cm}^{2}$. Tumor specimens were collected and snap frozen for immunohistochemistry to detect B7-H3 and CD3 expression.

Generation of Murine Bone Marrow Derived Dendritic Cells (BMDCs)

Femur bone was removed from C57BL/6J mice and sterilized by soaking in 70\% ethanol and then washed three times with phosphate buffer solution (PBS). Bone marrow cells were flushed out using PBS (Matheu et al., 2008). Red blood cells were removed by red blood cell lysis buffer. Mononuclear cells were seeded $\left(1 \times 10^{6}\right.$ cells per well) in non-tissue culture treated 24 -well plates and cultured with RPMI1640 medium (Gibco), 10\% FBS (Hyclone), 2mM GlutaMAX, $100 \mu \mathrm{M} \beta$-mercaptoethanol, 100 unit/mL of penicillin and $100 \mu \mathrm{g} / \mathrm{mL}$ of streptomycin) in the presence of murine GM-CSF (20 ng/mL; PeproTech) and changing medium every 2 days. At day 5 , cells were harvested and treated with $100 \mathrm{ng} / \mathrm{mL}$ lipopolysaccharide (LPS) (Invivogen). Two days later, BMDCs were harvested and assessed for the expression of CD11c and mB7-H3 by flow cytometry. BMDCs were then used in co-culture experiments with murine T cells.

Evaluate Toxicity of mB7-H3.CAR-Ts in C57BL/6J Immunocompetent Mice

Six weeks old male C57BL/6J mice were irradiated with 400 cGy to create a lymphodepleted environment to favor the expansion of adoptively transferred syngeneic $T$ cells. Two days post-irradiation, mice were infused i.v. with syngeneic control non-transduced T cells (NT), mCD19.CAR-Ts or mB7-H3.CAR-Ts $\left(1 \times 10^{7} /\right.$ mouse by i.v. injection). Five days after T cell infusion, we assessed the blood cell composition by flow cytometry and counting beads. Mice were then euthanized 15 - 16 days post T-cell infusion. Immune cell composition of the blood, spleen, bone marrow and lymph nodes was assessed by flow cytometry and counting beads. Tissues were also collected and evaluated by hematoxylin and eosin staining. A board-certified anatomic veterinary pathologist analyzed the slides at the Translational Pathology Laboratory at UNC. In parallel experiments, 6 - 8 weeks old C57BL/6J male mice received syngeneic NT, mCD29.CAR-Ts and mB7-H3.CAR-Ts $\left(1 \times 10^{7} /\right.$ mouse $)$ without irradiation.

\section{Murine PDAC Orthotopic Model in C57BL/6J Mice}

The murine PDAC tumor cell line KPC-4662 was engineered to express mB7-H3 at similar level as observed in human PDAC, and implanted into the pancreas of six weeks old C57BL/6J female mice by surgery $\left(1 \times 10^{5}\right.$ cells/mouse). Seventeen days post-tumor cell implantation, mice were irradiated with 400 cGy to create a lymphodepleted environment. Two days post-irradiation, mice were infused i.v. with syngeneic control NT or mB7-H3.CAR-Ts $\left(1 \times 10^{7}\right.$ cells/mouse). Tumor growth was monitored by US imaging. Mice were euthanized at day 33 - 34 post T-cell infusion. Immune cell composition of the blood, spleen, bone marrow and lymph nodes was assessed by flow cytometry and counting beads and tissues analyzed by immunohistochemistry using hematoxylin and eosin staining.

\section{Measurement of the Binding Affinity of the 376.96 mAb to Human and Murine B7-H3}

The binding affinity of the $376.96 \mathrm{mAb}$ for human and murine B7-H3 was determined by Microscale Thermophoresis (MST). The h4lgB7-H3-His (Novus Bio, Littleton, USA), h2lg-B7-H3-His (ACRO bio, Newark, USA) and mB7-H3-His (ACRO bio, Newark, USA) proteins were fluorescently labeled using RED-tris-NTA dye (NanoTemper Technology, Munich, Germany). Ten microliters of the labeled protein $(50 \mathrm{nM})$ was mixed with $10 \mu \mathrm{L}$ of the $376.96 \mathrm{mAb}$ (concentration varying between $1 \mathrm{nM}$ and $10 \mu \mathrm{M})$ in PBST buffer (PBS with $0.05 \%$ Tween 20 ) and loaded into 16 standard treated capillaries. The samples were excited by a Red LED at $50 \%$ power and the thermophoresis of each sample was measured at 60\% MST power on Monolith NT.115 (NanoTemper Technology, Munich, Germany).

\section{Stimulation of B7-H3.CAR-Ts with Plate-Bound B7-H3-Fc Fusion Proteins}

Non-tissue culture treated 96-well plates were coated with h4lg-B7-H3-Fc (AdipoGen Cor., Liestal, Switzerland), h2lg-B7-H3-Fc (ACRO bio, Newark, USA) and mB7-H3-Fc (ACRO bio, Newark, USA) proteins in $100 \mu \mathrm{L}$ PBS (concentration ranging between $10 \mathrm{nM}$ and $200 \mathrm{nM}$ ) for 24 hours at $4^{\circ} \mathrm{C}$. Plates were washed three times with DPBS, and $2 \times 10^{5} \mathrm{~B} 7-\mathrm{H} 3 . \mathrm{CAR}-28 \zeta-\mathrm{Ts}$ in $200 \mu \mathrm{L}$ of T cell medium were added to each well. Twenty four hours later, supernatants were collected and IFN $\gamma$ was measured by ELISA.

\section{Measurement of the Copy Numbers of mB7-H3.CAR}

Mice inoculated with mB7-H3-CAR-Ts were sacrificed on day 33 - 34 post CAR-Ts treatment, and spleens and tumors were harvested. Genomic DNA was extracted (Qiagen), and quantitative PCR (qPCR) performed using primers and probes (TaqMan TAMRA 
from Applied Biosystems, Thermo Fisher Scientific) spanning the scFv. qPCR was performed using the QuantStudio 6 Flex (Applied Biosystems, Thermo Fisher Scientific). Standard curves were prepared using serial dilutions of the mB7-H3.CAR plasmid. The copy number of unknown samples was interpolated from the standard curves using GraphPad Prism Software (La Jolla, CA).

\section{QUANTIFICATION AND STATISTICAL ANALYSIS}

The unpaired and nonparametric Mann Whitney test with two tailed p value calculation was used to measure differences between two groups. For multiple group comparisons, one-way ANOVA or two-way ANOVA was used to determine statistically significant differences between samples. Holm-Sidak test adjusted $p$ value $<0.05$ indicates a significant difference. Measurements were summarized as mean $\pm S D$ as noted in the figure legends. Difference between the bioluminescence of tumor and the survival curves were analyzed by the Chi-square test using GraphPad Prism v5. Experimental sample numbers ( $\mathrm{n}$ ) are indicated in the figure legends. The statistical analysis method is also described in the individual figure legends. Graph generation and statistical analyses were performed using the GraphPad Prism software (GraphPad, La Jolla, CA). 